\title{
An Assessment of Ares I-X Aeroacoustic Measurements with Comparisons to Pre-Flight Wind Tunnel Test Results
}

\author{
Donald K. Nance* \\ Jacobs ESTS Group, Huntsville, AL, 35806 \\ and \\ Darren K. Reed ${ }^{\dagger}$ \\ NASA Marshall Space Flight Center, Huntsville, AL, 35812
}

\begin{abstract}
During the recent successful launch of the Ares I-X Flight Test Vehicle, aeroacoustic data was gathered at fifty-seven locations along the vehicle as part of the Developmental Flight Instrumentation. Several of the Ares I-X aeroacoustic measurements were placed to duplicate measurement locations prescribed in pre-flight, sub-scale wind tunnel tests. For these duplicated measurement locations, comparisons have been made between aeroacoustic data gathered during the ascent phase of the Ares I-X flight test and wind tunnel test data. These comparisons have been made at closely matching flight conditions (Mach number and vehicle attitude) in order to preserve a one-to-one relationship between the flight and wind tunnel data. These comparisons and the current wind tunnel to flight scaling methodology are presented and discussed. The implications of using wind tunnel test data scaled under the current methodology to predict conceptual launch vehicle aeroacoustic environments are also discussed.
\end{abstract}

\section{Nomenclature}

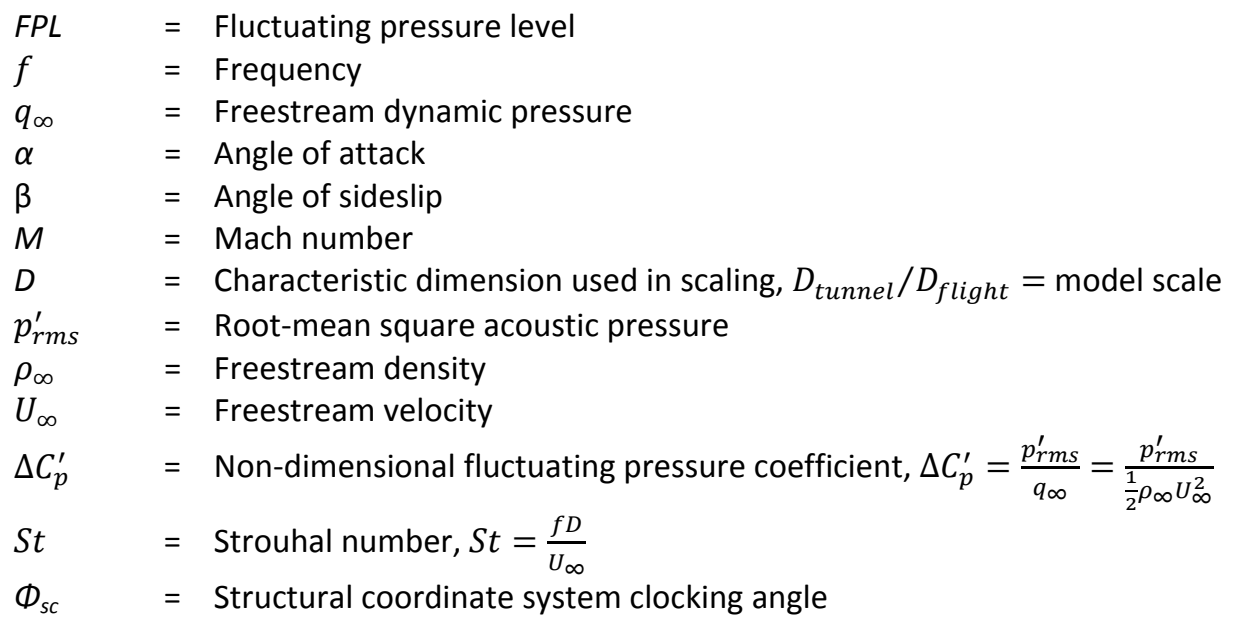

\footnotetext{
* Aerospace Engineer, Jacobs ESTS Group, EV33 Aerosciences Branch, NASA Marshall Space Flight Center, AIAA Member

${ }^{\dagger}$ Aeroacoustics Lead, EV33 Aerosciences Branch, NASA Marshall Space Flight Center, AIAA Member
} 


\section{Introduction}

$T_{c}^{+}$ HE Ares I-X was a development flight test vehicle (FTV) that was launched from the NASA Kennedy Space Center in October 2009. This flight offered a unique opportunity to capture flight data to aid in the design and development process of the Ares I Crew Launch Vehicle (CLV) within the Constellation Program. The Ares I-X FTV was defined such that the vehicle outer mold line and other key components were an acceptable representation of the Ares I CLV. The Ares I CLV is the replacement vehicle for continuation of manned space flight following retirement of the Space Transportation System in 2010.

As part of the Ares I-X Developmental Flight Instrumentation (DFI), aeroacoustic data was gathered at 57 locations along the flight test vehicle. Several of the Ares I-X aeroacoustic DFI measurements were placed to duplicate measurement locations utilized in pre-flight, sub-scale wind tunnel tests. For those locations that are consistent between the flight and wind tunnel tests, comparisons have been made between aeroacoustic data gathered during the ascent flight and wind tunnel data gathered on sub-scale models of the Ares I-X FTV and Ares I CLV. These comparisons have been made at closely matching flight conditions (vehicle attitude and Mach number) in order to preserve a one-to-one relationship between the flight and wind tunnel data.

\section{Ares I-X Vehicle Description}

The Ares I-X FTV was a stacked vehicle that consisted of three primary stack elements: the First Stage (FS), Upper Stage Simulator (USS), and Crew Module (CM)/Launch Abort System (LAS) simulator. An active Roll Control System (RoCS) positioned on the USS was also included in the Ares I-X vehicle. The FS was comprised of a foursegment Space Shuttle Re-useable Solid Rocket Motor (RSRM), a dummy (no propellant) fifth segment, a forward skirt, a forward skirt extension, and a frustum. The Ares I-X USS was made up of an Interstage positioned atop the FS, a simulator of the Ares I CLV Upper Stage (US), and simulators for the Crew Exploration Vehicle (CEV) Spacecraft Adapter (SA) and Service Module (SM). The CM/LAS simulator is a physical representation of the Ares I CEV CM/LAS. A schematic of the Ares I-X FTV is shown in Figure 1.

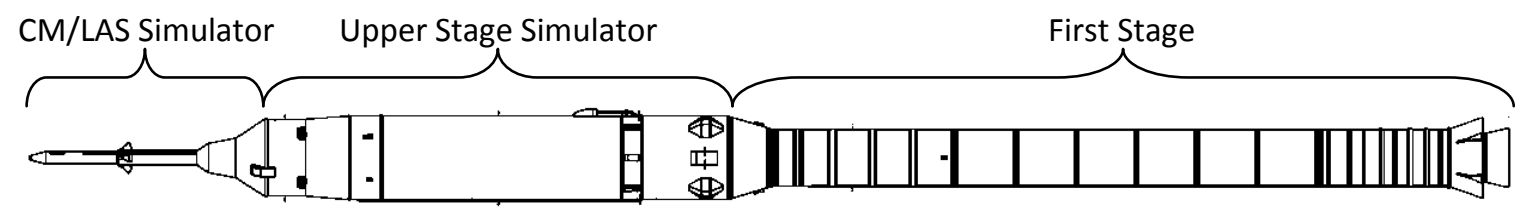

Figure 1. Ares I-X Flight Test Vehicle.

\section{Ares I-X Aeroacoustic Developmental Flight Instrumentation}

Aeroacoustic fluctuating pressure data was acquired at 57 locations along the Ares I-X FTV. Twenty-six (26) measurements were positioned on the CM/LAS simulator, 22 on the USS, and nine on the FS. Ares I-X aeroacoustic DFI measurement locations are depicted in Figure 2. Two transducer models were utilized-Kulite ${ }^{\circledR}$ models XTL186C-190-20A and LLE-1-080-20A. Due to the large data storage requirements inherent when collecting aeroacoustic data and the limited amount of available storage space within the flight test data acquisition system, some measurements were sampled at a rate of $10.4 \mathrm{KHz}$ while others were sampled at $5.2 \mathrm{kHz}$. Data were acquired via on-board recorders for a duration extending from ten seconds prior to engine ignition until FS splash down. 


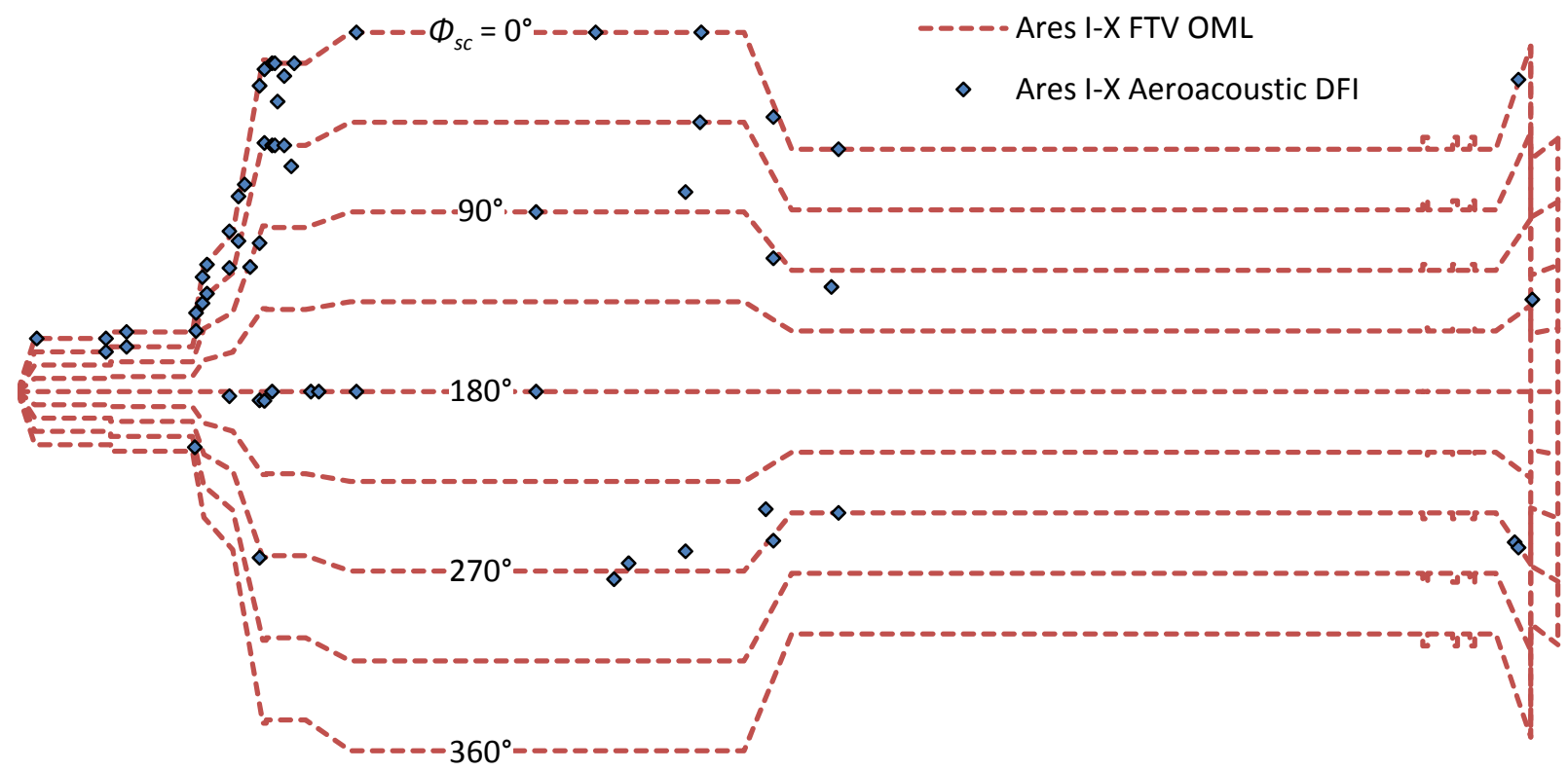

Figure 2. Ares I-X Aeroacoustic DFI Layout.

\section{Ares I Vehicle Description}

The Ares I CLV is conceptually comprised of four primary stack elements: the First Stage (FS), Upper Stage (US), Orion Crew Exploration Vehicle (CEV), and Launch Abort System (LAS). The Ares I FS is a single, five-segment solid rocket booster derived from the four-segment Redesigned Solid Rocket Booster (RSRB) used during the Space Shuttle program. A newly designed forward adapter mates the First Stage to the newly designed Ares I US. The US is propelled by a J-2X main engine fueled with liquid oxygen and liquid hydrogen. The J-2X is an evolved variation of two earlier predecessors: the powerful J-2 engine that propelled the Apollo-era Saturn IB and Saturn V rockets, and the J-2S, a simplified version of the J-2 developed and tested in the early 1970s. The Orion Crew Exploration Vehicle (CEV), consisting of the Spacecraft Adapter (SA), Service Module (SM), and Crew Module (CM), sits atop the Upper Stage. Attached to the Orion is the Launch Abort System (LAS). A drawing of the Ares I CLV is shown in Figure 3.

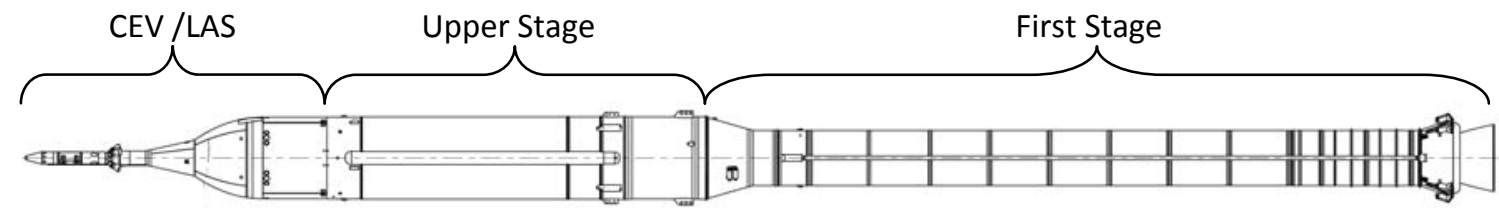

Figure 3. Ares I Crew Launch Vehicle.

\section{Wind Tunnel Test Programs}

During the NASA Constellation Program, numerous development-phase wind tunnel test programs have been conducted. Relevant test programs that included aeroacoustic measurements were designated TDT-599 and AlISA001. Program TDT-599 was conducted by the NASA Langley Research Center (LaRC) Aeroelasticity Branch, and its primary objective was to investigate the aero-buffet phenomena for the Ares I-X FTV. Defining the ascentphase aeroacoustic environments for the Ares I CLV Upper Stage and First Stage was the primary objective during program Al-ISA001, conducted by the NASA Marshall Space Flight Center (MSFC) Aerosciences Branch. As 
previously mentioned, some of the aeroacoustic measurement locations prescribed in both test programs were duplicated on the Ares I-X FTV flight test.

\section{A. Wind Tunnel Test Program TDT-599}

Test program TDT-599 was conducted in the NASA LaRC $16 \times 16$-foot Transonic Dynamics Tunnel (TDT). The primary objective of the test was to acquire buffet bandwidth $(<60 \mathrm{~Hz})$ time-correlated unsteady pressure data at transonic conditions. In addition, 32 channels of aeroacoustic bandwidth $(>60 \mathrm{~Hz}$ ) fluctuating pressure data were obtained as a secondary objective. Measurements were made at Mach numbers ranging from 0.5 to 1.2 for angles of attack and sideslip between \pm 8 degrees. Tetrafluoroethane (or R-134a) and air were utilized as the test media.

The test article was a 3.5-percent scale full-stack model based on the Ares I-X FTV ascent configuration. Two model configurations, one complete with all protuberances and another with no protuberances, were tested. It should be noted that only the protuberance-on data was analyzed during this work. Test article instrumentation included 32 Kulite $^{\circledR}$ ultra-miniature unsteady pressure transducers (models XCL-072-15D and XCL-093-15D). Figure 4 shows the aeroacoustic transducer locations utilized in test program TDT-599. Aeroacoustic bandwidth fluctuating pressure time histories were simultaneously acquired at a rate of $100 \mathrm{kHz}$ for a duration of 10 seconds.

Further details concerning the test program TDT-599 are available in Reference 1.

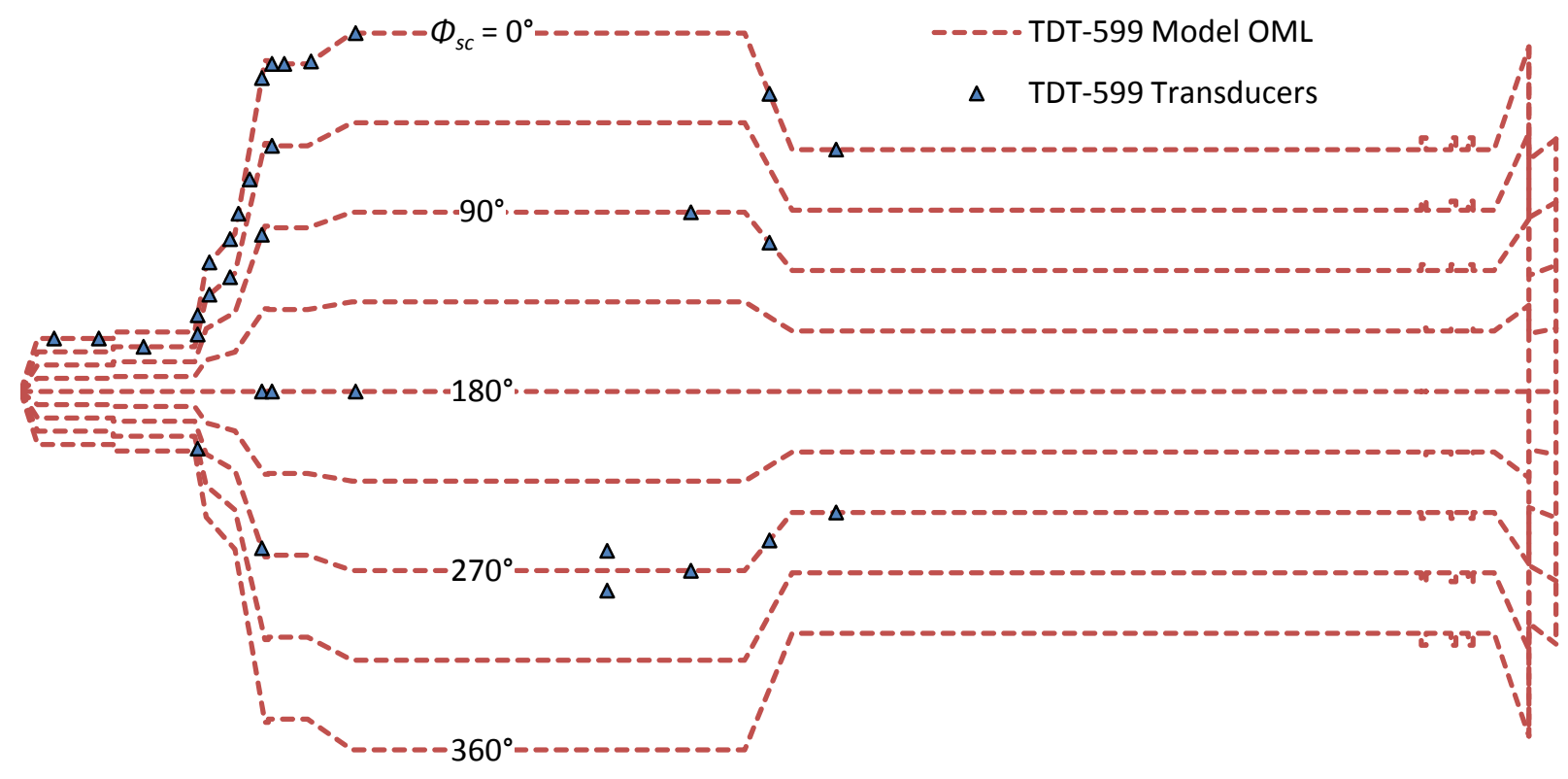

Figure 4. TDT-599 Transducer Layout.

\section{B. Wind Tunnel Test Program Al-ISA001}

Test program AI-ISA001 was conducted at the NASA Ames Research Center (ARC) Unitary Plan Wind Tunnels. Both the 11x11-foot Transonic Wind Tunnel (TWT) and the 9x7-foot Supersonic Wind Tunnel (SWT) were used. The primary objective of the test was to acquire aeroacoustic fluctuating pressure data under non-abort ascent flight conditions. Aeroacoustic fluctuating pressure data were obtained at Mach numbers ranging from 0.5 to 2.5 for angles of attack and sideslip between \pm 7 degrees.

The test utilized a newly fabricated 4.0-percent scale model representing the Ares I CLV ascent configuration. Due to size constraints in the wind tunnel, the model was truncated on the FS at a point equivalent to the midpoint of the fifth segment. A single configuration, complete with all aerodynamically significant protuberances and OML deviations, was tested. The model was instrumented with 150 Kulite $^{\circledR}$ ultra-miniature unsteady pressure transducers (models XCL-072-5D and XCL-072-15D). Transducer locations are illustrated in Figure 5. Fluctuating pressure time histories were captured with a dual-speed acquisition system. The system acquired data 
simultaneously at a low frequency rate of $6.4 \mathrm{kHz}$ and a high frequency rate of $192 \mathrm{kHz}$. The low frequency data was acquired for approximately 12 seconds, and the high frequency data was sampled for roughly 2 seconds.

See Reference 2 for further details about the test program AI-ISA001.

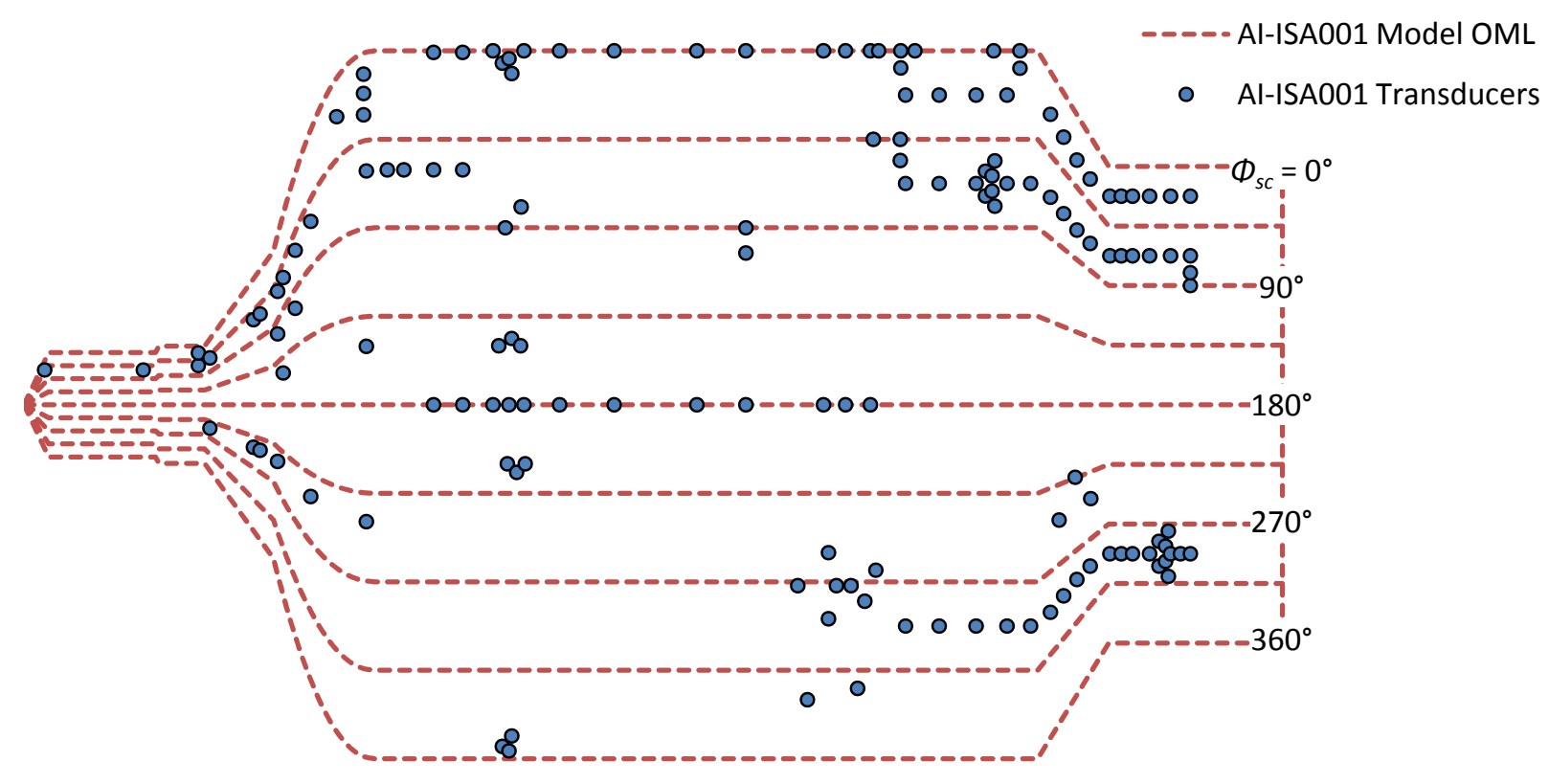

Figure 5. Al-ISA001 Transducer Layout.

\section{Data Processing and Scaling}

Aeroacoustic data comparisons are most often made in spectral form. For the Ares I-X flight data and the wind tunnel data presented herein, such spectral comparison required the conversion of time domain data into the frequency domain. All time history fluctuating pressure data were Fourier-analyzed to provide narrowband and one-third octave aeroacoustic spectra and overall fluctuating pressure levels. To facilitate one-to-one comparisons with the flight data, the model-scale spectra narrowband resulting from the wind tunnel data were scaled to Ares $\mathrm{I}-\mathrm{X}$ flight conditions prior to one-third band and overall level integration.

\section{A. Ares I-X Flight Data}

Two-second time slices of the Ares I-X DFI aeroacoustic data were Fast Fourier Transform (FFT) analyzed to provide narrowband spectra. Each two-second time slice was associated with a mean set of flight conditions (attitude, Mach number, dynamic pressure, etc.) as determined via simple mean statistical analysis of flight conditions for each time slice. The DFI narrowband spectra were integrated to produce one-third octave spectra ranging from $20 \mathrm{~Hz}$ to $2 \mathrm{kHz}$ and overall fluctuating pressure levels.

\section{B. Wind Tunnel Test Data}

Wind tunnel test fluctuating pressure time histories were Fourier-analyzed, scaled from tunnel to flight conditions, and integrated to produce one-third octave spectra and overall fluctuating pressure levels. The time history fluctuating pressure data were first processed to model-scale narrowband spectral form via FFT analysis. Due to differences in geometric scale and flow conditions, wind tunnel data were scaled to full-scale vehicle flight conditions. Adjustments were made to both fluctuating pressure spectra amplitude and frequency.

In scaling the fluctuating pressure spectra amplitude, the non-dimensional fluctuating pressure coefficient, $\Delta C_{p}^{\prime}$, at a given vehicle location was assumed to be equal between the wind tunnel and flight conditions. 


$$
\left(\Delta C_{p}^{\prime}\right)_{\text {flight }}=\left(\Delta C_{p}^{\prime}\right)_{\text {tunnel }}
$$

Thus, using the basic definition of fluctuating pressure level, the amplitude scales as function of the flight-to-windtunnel dynamic pressure ratio.

$$
F P L_{\text {full-scale }}=F P L_{\text {model-scale }}+20 \log _{10}\left(\frac{q_{\text {flight }}}{q_{\text {tunnel }}}\right), d B \text { re } 20 \mu P a
$$

To scale the fluctuating pressure spectra frequency, the non-dimensional Strouhal number was assumed to be equivalent between the wind tunnel and flight conditions.

$$
S t_{\text {flight }}=S t_{\text {tunnel }}
$$

Hence, the frequency shift between the wind tunnel and flight conditions is a function of the geometric scale of the model and the flight-to-wind-tunnel velocity ratio.

$$
f_{\text {full-scale }}=f_{\text {model-scale }}\left(\frac{D_{\text {tunnel }}}{D_{\text {flight }}}\right)\left(\frac{\left(U_{\infty}\right)_{\text {flight }}}{\left(U_{\infty}\right)_{\text {tunnel }}}\right)
$$

The resulting full-scale narrowband spectra were integrated into one-third octave bands ranging from $20 \mathrm{~Hz}$ to $2 \mathrm{kHz}$. Full-scale overall fluctuating pressure levels (OAFPL) were calculated by log summing narrowband levels over the entire bandwidth.

\section{Flight-to-Wind Tunnel Comparisons}

Several of the Ares I-X aeroacoustic DFI measurements were positioned to duplicate measurement locations employed in pre-flight wind tunnel tests. These consistent measurements allow for the unique opportunity of making direct comparisons between flight data and scaled wind tunnel test results. Comparisons have been made between aeroacoustic data gathered during the Ares I-X ascent flight and wind tunnel data gathered on sub-scale models of the Ares I-X FTV and Ares I CLV. These comparisons have been made at closely matching flight conditions (vehicle attitude and Mach number) in order to preserve a one-to-one relationship between the flight data and wind tunnel test results.

\section{Conclusions/Recommendations}

\section{References}

${ }^{1}$ Piatak, D. J., Florance, J. P., Ivanco, T. G., Rausch, R. D., Sekula, M. K., and Wiesman C. D., Test Summary Document for the 3.5 Percent Ares I-X Rigid Buffet/Aeroacoustic Model in the Transonic Dynamics Tunnel, NASA LaRC Aeroelasticity Branch, ARES-AE-TA-0002, January 31, 2008.

${ }^{2}$ Hamilton, C. R., Mayle, M. N., Crosby, W. A., Nance, D. K., and Reed, D. K., Ascent Acoustics Test of a $4 \%-S c a l e$ Ares I Model in the NASA Ames Research Center Unitary Plan Wind Tunnels, ESTSG-FY09-00450, February 2009. 


\title{
An Assessment of Ares I-X Aeroacoustic Measurements with Comparisons to Pre-Flight Wind Tunnel Test Results
}

\author{
Darren K. Reed ${ }^{*}$ \\ NASA Marshall Space Flight Center, Huntsville, AL, 35812 \\ Melody N. Mayle \\ NASA Marshall Space Flight Center, Huntsville, AL 35812 \\ Donald K. Nance ${ }^{\S}$ \\ Georgia Tech Research Institute, Smyrna, GA 30080
}

\begin{abstract}
During the successful launch of the Ares I-X Flight Test Vehicle, aeroacoustic fluctuating pressure data was measured at fifty-seven locations along the vehicle as part of the Developmental Flight Instrumentation. Several of these Ares I-X aeroacoustic measurements were placed at locations that duplicate those utilized in pre-flight, sub-scale wind tunnel tests. For these duplicated measurement locations, aeroacoustic data gathered during wind tunnel tests aeroacoustic and data gathered during the ascent phase of the Ares I-X flight test have been compared. These comparisons were made at closely matching flight conditions in order to preserve a one-to-one relationship between the wind tunnel and flight test data. These comparisons, along with vehicle descriptions, wind tunnel test programs, and the current wind-tunnel-to-flight data processing and scaling methodology, are presented and discussed. The implications of using scaled wind tunnel test data in order to predict conceptual launch vehicle aeroacoustic environments with this current methodology are also discussed.
\end{abstract}

\section{Nomenclature}

FPL $\quad=$ Fluctuating pressure level

$f \quad=$ Frequency

$q_{\infty} \quad=$ Freestream dynamic pressure

$\alpha \quad=$ Angle of attack

b $\quad=$ Angle of sideslip

$M=$ Mach number

$D \quad=$ Characteristic dimension used in scaling, $D_{\text {tunnel }} / D_{\text {flight }}=$ model scale

$p_{r m s}^{\prime}=$ Root-mean-square acoustic pressure

$\rho_{\infty} \quad=$ Freestream density

$U_{\infty} \quad=$ Freestream velocity

$\Delta C_{p}^{\prime}=$ Non-dimensional fluctuating pressure coefficient, $\Delta C_{p}^{\prime}=\frac{p_{r m s}^{\prime}}{q_{\infty}}=\frac{p_{r m s}^{\prime}}{\frac{1}{2} \rho_{\infty} U_{\infty}^{2}}$

$S t \quad=$ Strouhal number, $S t=\frac{f D}{U_{\infty}}$

$\phi_{s c} \quad=$ Structural coordinate system clocking angle

\footnotetext{
* Aeroacoustics Lead, MSFC Aerosciences Branch

${ }^{\ddagger}$ Aerospace Engineer, MSFC Aerosciences Branch

$\S$ Senior Research Engineer, Georgia Tech Research Institute, AIAA Member
} 


\section{Introduction}

$A^{\text {nis }}$ RES I-X was a flight test vehicle (FTV) launched from the NASA Kennedy Space Center in October 2009. This launch offered a unique opportunity to capture flight data to aid in the design and development process of the Ares I Crew Launch Vehicle (CLV) within the Constellation Program. The Ares I-X FTV was defined such that its outer mold line and other key components were a suitable representation of the Ares I CLV, which is the replacement vehicle for continuation of manned space flight following retirement of the Space Transportation System in 2011.

As part of the Ares I-X Developmental Flight Instrumentation (DFI), aeroacoustic flight data was measured at 57 locations along the flight test vehicle. Several of these Ares I-X DFI transducers were placed at locations that duplicate those utilized in pre-flight, sub-scale wind tunnel tests. For these duplicated transducer locations, aeroacoustic data gathered on scale models of the Ares I-X FTV and Ares I CLV, and aeroacoustic data gathered during the ascent phase of the Ares I-X FTV have been compared. These comparisons were made at closely matching flight conditions (Mach number) in order to preserve a one-to-one relationship between the wind tunnel and flight test data.

\section{Ares I-X Vehicle Description}

The Ares I-X FTV was a vehicle that consisted of three primary stack elements: the First Stage (FS), Upper Stage Simulator (USS), and Crew Module (CM)/Launch Abort System (LAS) simulator. An active Roll Control System (RoCS) positioned on the USS was also included on the Ares I-X vehicle. The FS was comprised of a four-segment Space Shuttle Re-useable Solid Rocket Motor (RSRM), a dummy (no propellant) fifth segment, a forward skirt, a forward skirt extension, and a frustum. The Ares I-X USS was comprised of an Interstage (IS) positioned atop the FS, a simulator of the Ares I CLV Upper Stage (US), and simulators for the Crew Exploration Vehicle (CEV) Spacecraft Adapter (SA) and Service Module (SM). The CM/LAS simulator is a physical representation of the Ares I CEV CM/LAS. A schematic of the Ares I-X FTV is shown in Figure 1.

The primary difference between the Ares I-X and the Ares I configuration is that the Service Module and Spacecraft Adapter were merged into the Extended Service Module at a larger diameter and the Crew Module is now encapsulated by an ogive fairing for the Ares I vehicle.

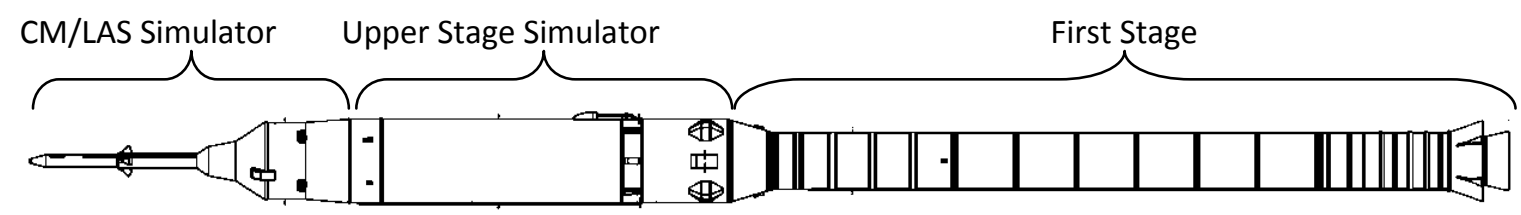

Figure 1. Ares I-X Flight Test Vehicle.

\section{Ares I-X Aeroacoustic Developmental Flight Instrumentation}

Aeroacoustic data was acquired at 57 locations along the Ares I-X FTV. Nine measurements were positioned on the FS, 22 on the USS, and 26 on the CM/LAS simulator. The Ares I-X aeroacoustic DFI measurement locations are depicted in Figure 2. Two transducer models were utilized: Kulite ${ }^{\circledR}$ models XTL-186C-190-20A and LLE-1-080-20A. Due to the large data storage requirements inherent when collecting aeroacoustic data and the limited amount of available storage space within the flight test data acquisition system, some measurements were sampled at a rate of $10.4 \mathrm{kHz}$ while others were sampled at $5.2 \mathrm{kHz}$. Data were acquired via on-board recorders for a duration extending from ten seconds prior to engine ignition until FS splash down. 

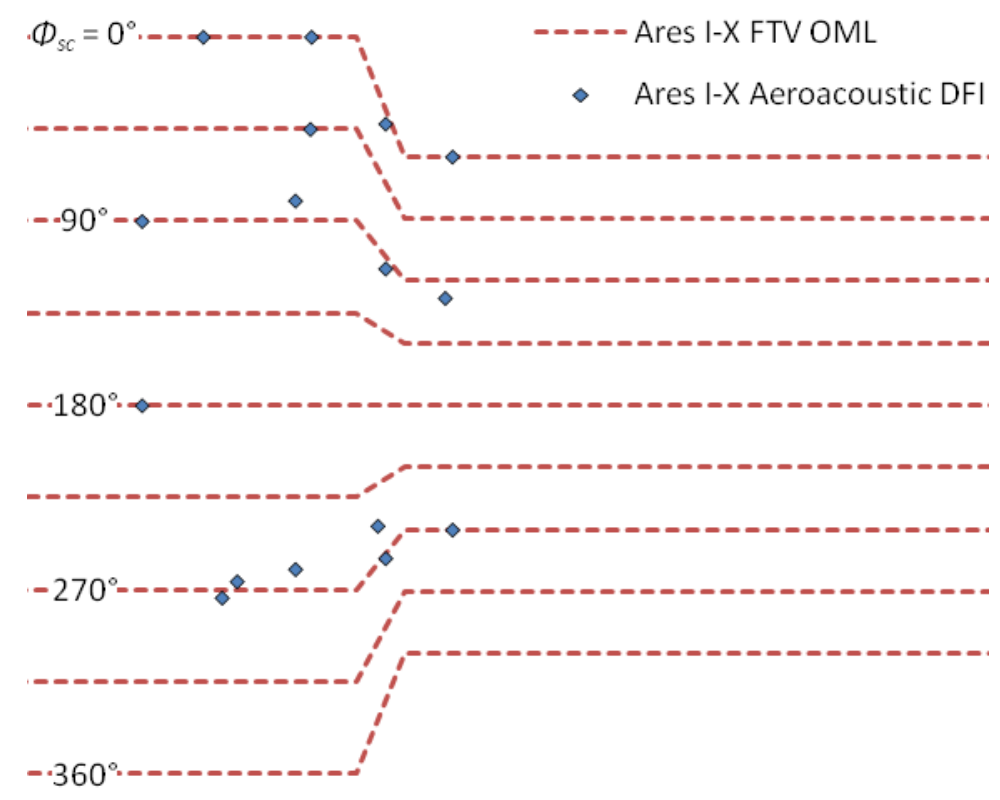

Figure 2. Ares I-X Aeroacoustic DFI Layout.

\section{Ares I Vehicle Description}

The Ares I CLV is conceptually comprised of four primary stack elements: the First Stage (FS), Upper Stage (US), Orion Crew Exploration Vehicle (CEV), and Launch Abort System (LAS). The Ares I FS is a single, five-segment solid rocket booster derived from the four-segment Redesigned Solid Rocket Booster (RSRB) used during the Space Shuttle program. A newly designed forward adapter mates the First Stage to the newly designed Ares I US. The US is propelled by a J-2X main engine fueled with liquid oxygen and liquid hydrogen. The $\mathrm{J}-2 \mathrm{X}$ is an evolved variation of two earlier predecessors: the powerful J-2 engine that propelled the Apollo-era Saturn IB and Saturn V rockets, and the J-2S, a simplified version of the J-2 developed and tested in the early 1970s. The Orion CEV, consisting of the Service Module (SM), and Crew Module (CM), sits atop the Upper Stage. Attached to the Orion is the Launch Abort System (LAS). A drawing of the Ares I CLV is shown in Figure 3.

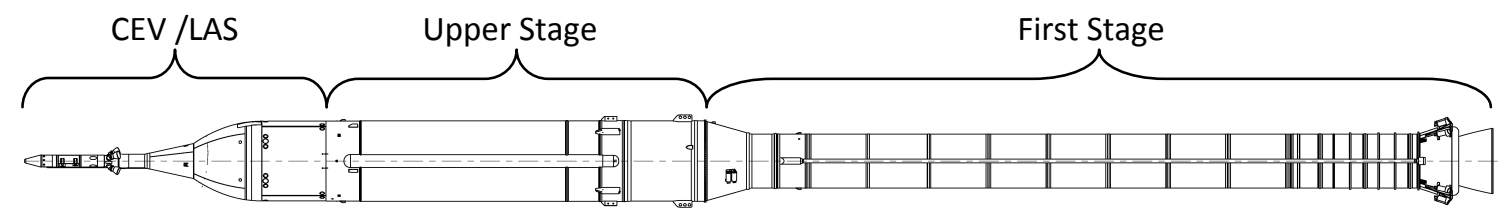

Figure 3. Ares I Crew Launch Vehicle.

\section{Wind Tunnel Test Programs}

During the NASA Constellation Program, numerous development-phase wind tunnel test programs were conducted. Relevant test programs that included aeroacoustic fluctuating pressure measurements were designated TDT-599 and AI-ISA001. The primary objective of test program TDT-599, conducted by the NASA Langley Research Center (LaRC) Aeroelasticity Branch, was to investigate the aero-buffet phenomena for the Ares I-X FTV. The primary objective of test program AI-ISA001, conducted by the NASA Marshall Space Flight Center 
(MSFC) Aerosciences Branch, was to define the non-abort ascent-phase aeroacoustic environments for the Ares I CLV Upper Stage and First Stage. As previously mentioned, some of the aeroacoustic measurement locations prescribed in both test programs were duplicated on the Ares I-X FTV flight test.

\section{A. Wind Tunnel Test Program TDT-599}

Test program TDT-599 was conducted in the NASA LaRC 16x16-foot Transonic Dynamics Tunnel (TDT). The primary objective of the test was to acquire buffet bandwidth $(<60 \mathrm{~Hz})$ time-correlated unsteady pressure data at transonic conditions. A secondary objective was to acquire aeroacoustic bandwith $(>60 \mathrm{~Hz})$ fluctuating pressure data, which utilized 32 additional channels. Measurements were obtained at Mach numbers ranging from 0.5 to 1.2 for angles of attack and sideslip between \pm 8 degrees. Tetrafluoroethane (or R-134a) and air were utilized as the test media.

The test article was a 3.5-percent scale full-stack model representing the Ares I-X FTV ascent configuration. Two model configurations, one complete with all protuberances and another with no protuberances, were tested. (It should be noted that only the protuberance-on data was analyzed during this work.) The test article was instrumented with 32 Kulite $^{\circledR}$ ultra-miniature unsteady pressure transducers (models XCL-072-15D and XCL-09315D). Figure 4 shows the aeroacoustic transducer locations utilized in test program TDT-599. Aeroacoustic bandwidth fluctuating pressure time histories were simultaneously acquired at a rate of $100 \mathrm{kHz}$ for a duration of 10 seconds.

Further details regarding the test program TDT-599 are available in Reference 1.
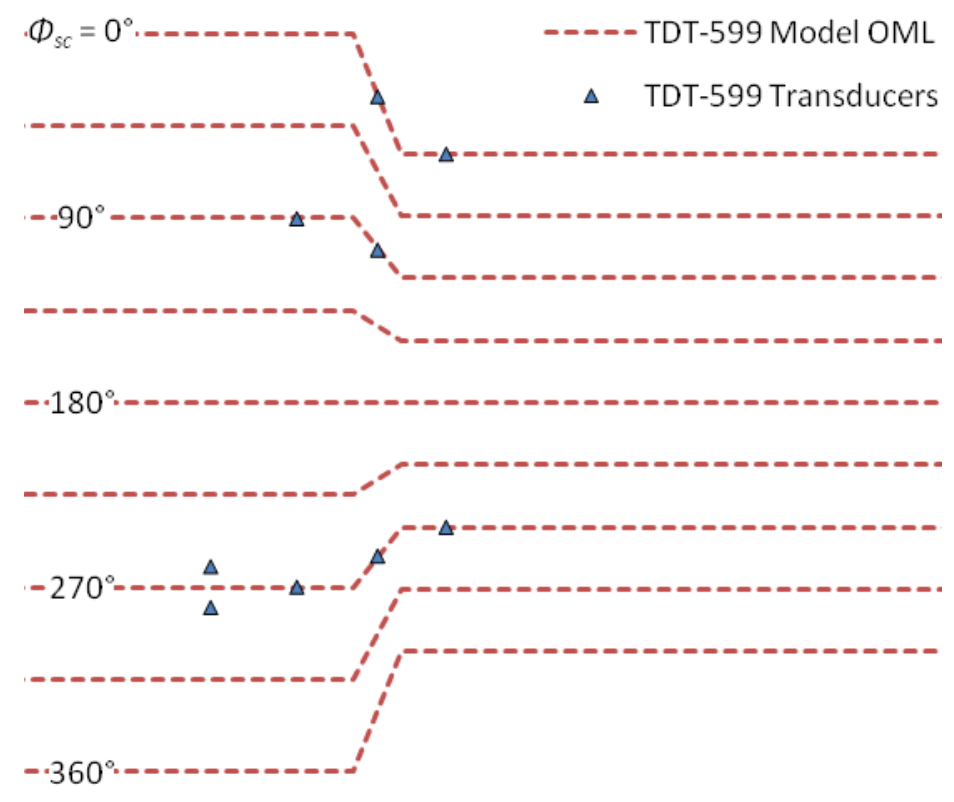

Figure 4. TDT-599 Transducer Layout.

\section{B. Wind Tunnel Test Program Al-ISA001}

Test program AI-ISA001 was conducted in both the NASA Ames Research Center (ARC) 11x11-foot Transonic and 9x7-foot Supersonic Unitary Plan Wind Tunnels. The primary test objective was to acquire aeroacoustic fluctuating pressure data under non-abort ascent flight conditions. Measurements were obtained at Mach numbers ranging from 0.5 to 2.5 for angles of attack and sideslip between \pm 7 degrees.

The test article was a newly fabricated 4.0-percent scale model representing the Ares I CLV ascent configuration. Due to size constraints in the wind tunnel, the model was truncated on the FS at a point equivalent to the mid-point of the forward motor segment. A single configuration, complete with all aerodynamically significant protuberances and OML deviations, was tested. The test article was instrumented with 150 Kulite $^{\circledR}$ 
ultra-miniature unsteady pressure transducers (models XCL-072-5D and XCL-072-15D). Figure 5 shows the aeroacoustic transducer locations utilized in test program Al-ISA001. Fluctuating pressure time histories were captured with a dual-speed acquisition system. The system acquired data simultaneously at a low frequency rate of $6.4 \mathrm{kHz}$ and a high frequency rate of $192 \mathrm{kHz}$. The low frequency data was acquired for approximately 12 seconds and the high frequency data was sampled for roughly 2 seconds.

Further details regarding the AI-ISA001 test program are available in Reference 2.

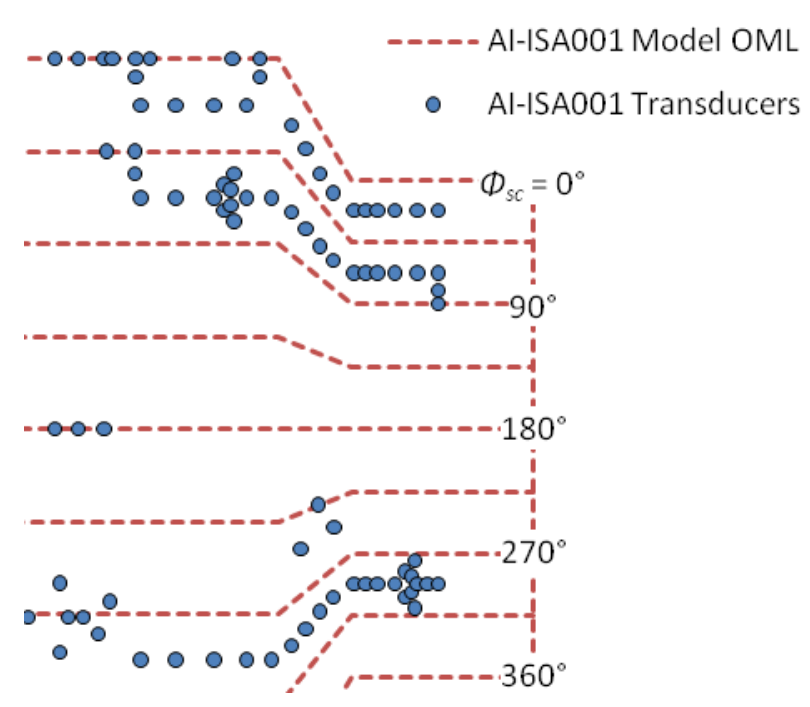

Figure 5. AI-ISA001 Transducer Layout.

\section{Data Processing and Scaling}

Aeroacoustic data comparisons are most often made in spectral form. For the Ares I-X flight data and wind tunnel test data presented herein, such spectral comparison required a conversion from the time domain into the frequency domain. All time history fluctuating pressure data were Fourier-analyzed to provide narrowband and one-third octave aeroacoustic spectra and overall fluctuating pressure levels. To facilitate one-to-one comparisons with the flight data, the model-scale spectra narrowband resulting from the wind tunnel data were scaled to Ares $\mathrm{I}-\mathrm{X}$ flight conditions prior to one-third band and overall level integration.

\section{A. Ares I-X Flight Data}

Two-second time slices of the Ares I-X DFI aeroacoustic data were Fast Fourier Transform (FFT) analyzed to provide narrowband spectra. Each two-second time slice was associated with a mean set of flight conditions (Mach number, attitude, dynamic pressure, etc.) as determined by simple mean statistical analysis. The DFI narrowband spectra were integrated to produce one-third octave bands ranging from $20 \mathrm{~Hz}$ to $2 \mathrm{kHz}$ and overall fluctuating pressure levels.

\section{B. Wind Tunnel Test Data}

Wind tunnel test fluctuating pressure time histories were Fourier-analyzed, scaled from tunnel to flight conditions, and integrated to produce one-third octave spectra and overall fluctuating pressure levels. The time history fluctuating pressure data were first processed to model-scale narrowband spectral form via FFT analysis. Due to differences in geometric scale and flow conditions, wind tunnel data were scaled to full-scale vehicle flight conditions. Adjustments were made to both fluctuating pressure spectra amplitude and frequency. 
In scaling the fluctuating pressure spectra amplitude, the non-dimensional fluctuating pressure coefficient, $\Delta C_{p}^{\prime}$, at a given vehicle location was assumed to be equivalent between the wind tunnel and flight conditions.

$$
\left(\Delta C^{\prime}{ }_{p}\right)_{\text {flight }}=\left(\Delta C^{\prime}{ }_{p}\right)_{\text {tunnel }}
$$

Thus, using the basic definition of fluctuating pressure level, the amplitude scales as a function of the flight-towind-tunnel dynamic pressure ratio.

$$
F P L_{\text {full-scale }}=F P L_{\text {model-scale }}+20 \log _{10}\left(\frac{q_{\text {flight }}}{q_{\text {tunnel }}}\right), d B \text { re } 20 \mu P a
$$

To scale the fluctuating pressure spectra frequency, the non-dimensional Strouhal number was assumed to be equivalent between the wind tunnel and flight conditions.

$$
S t_{\text {flight }}=S t_{\text {tunnel }}
$$

Hence, the frequency shift between the wind tunnel and flight conditions is a function of the geometric scale of the model and the flight-to-wind-tunnel velocity ratio.

$$
f_{\text {full-scale }}=f_{\text {model-scale }}\left(\frac{D_{\text {tunnel }}}{D_{\text {flight }}}\right)\left(\frac{\left(U_{\infty}\right)_{\text {flight }}}{\left(U_{\infty}\right)_{\text {tunnel }}}\right)
$$

The resulting full-scale narrowband spectra were integrated to produce one-third octave bands ranging from 20 to $2000 \mathrm{~Hz}$. Full-scale overall fluctuating pressure levels (OAFPL) were calculated by log summing narrowband levels over the entire bandwidth.

\section{Flight-to-Wind Tunnel Comparisons}

Several of the Ares I-X DFI aeroacoustic fluctuating pressure transducers were placed at locations that duplicate those utilized in pre-flight, sub-scale wind tunnel tests. For these duplicated transducer locations, data measured during the wind tunnel tests and data measured during the ascent phase of the Ares I-X flight test have been compared. These comparisons were made at closely matching flight conditions (Mach number) in order to preserve a one-to-one relationship between the wind tunnel and flight test data.

Twelve of the 57 Ares I-X transducers along with their respective pre-flight (wind tunnel) predictions are shown below. Transducers OAD819P, OAD820P, OAD821P, and OAD822P were located on the LAS near the abort motor nozzles (Figure 6).

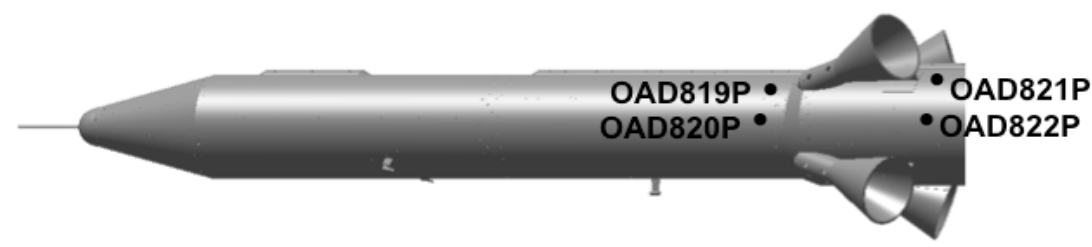

Figure 6. Transducers OAD819P, OAD920P, OAD921P, and OAD922P Locations 
Transducers OAD819P and OAD820P and their predictions can be seen in Figure 7. Transducers OAD821P and OAD822P and their prediction can be seen Figure 8. OAD819P measured supersonic data were greater than expected, and OAD821P and OAD822P measured data were much less than expected.

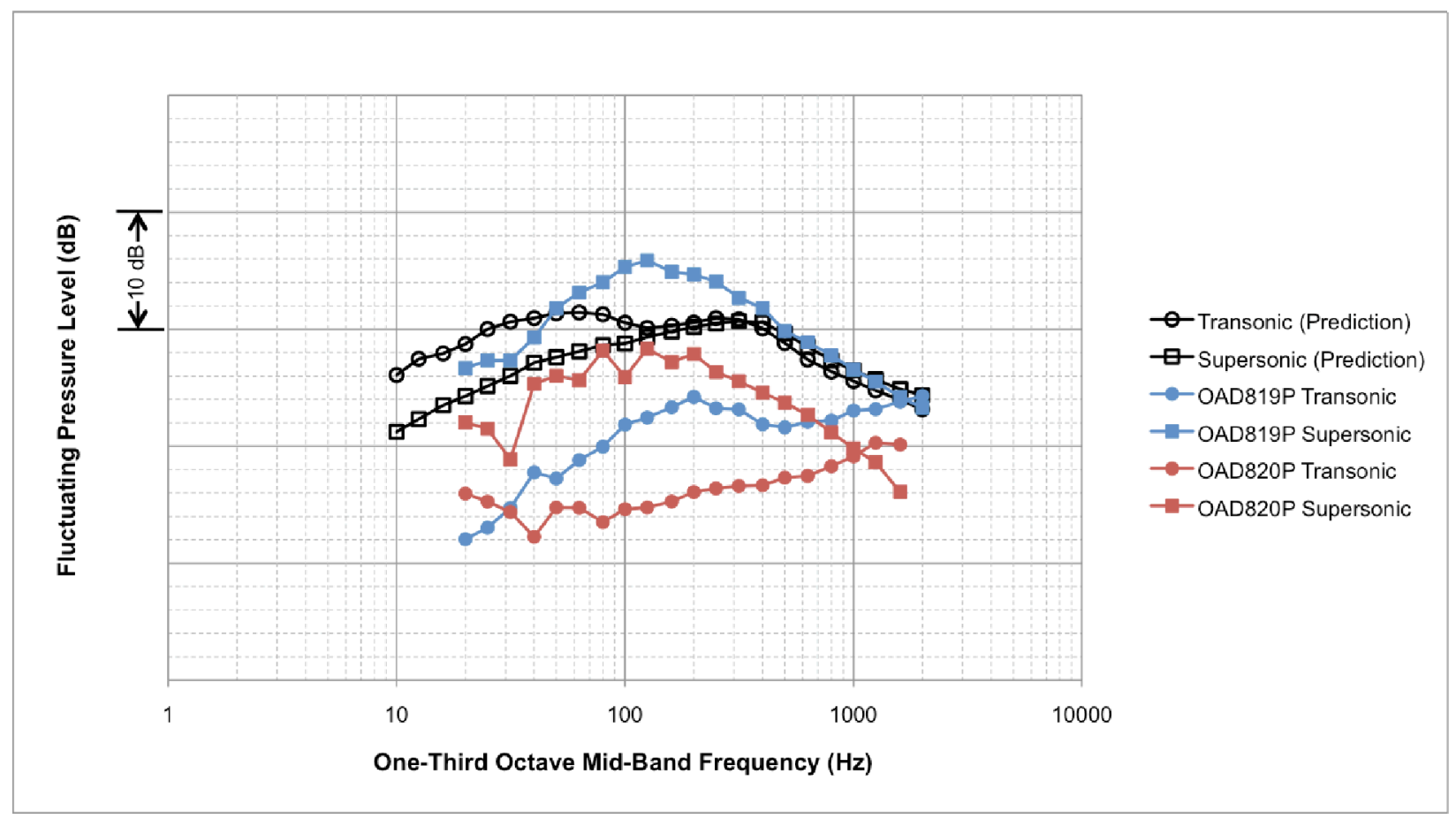

Figure 7. Transducers OAD819P and OAD820P One-Third Octave Spectra with Pre-flight Predictions

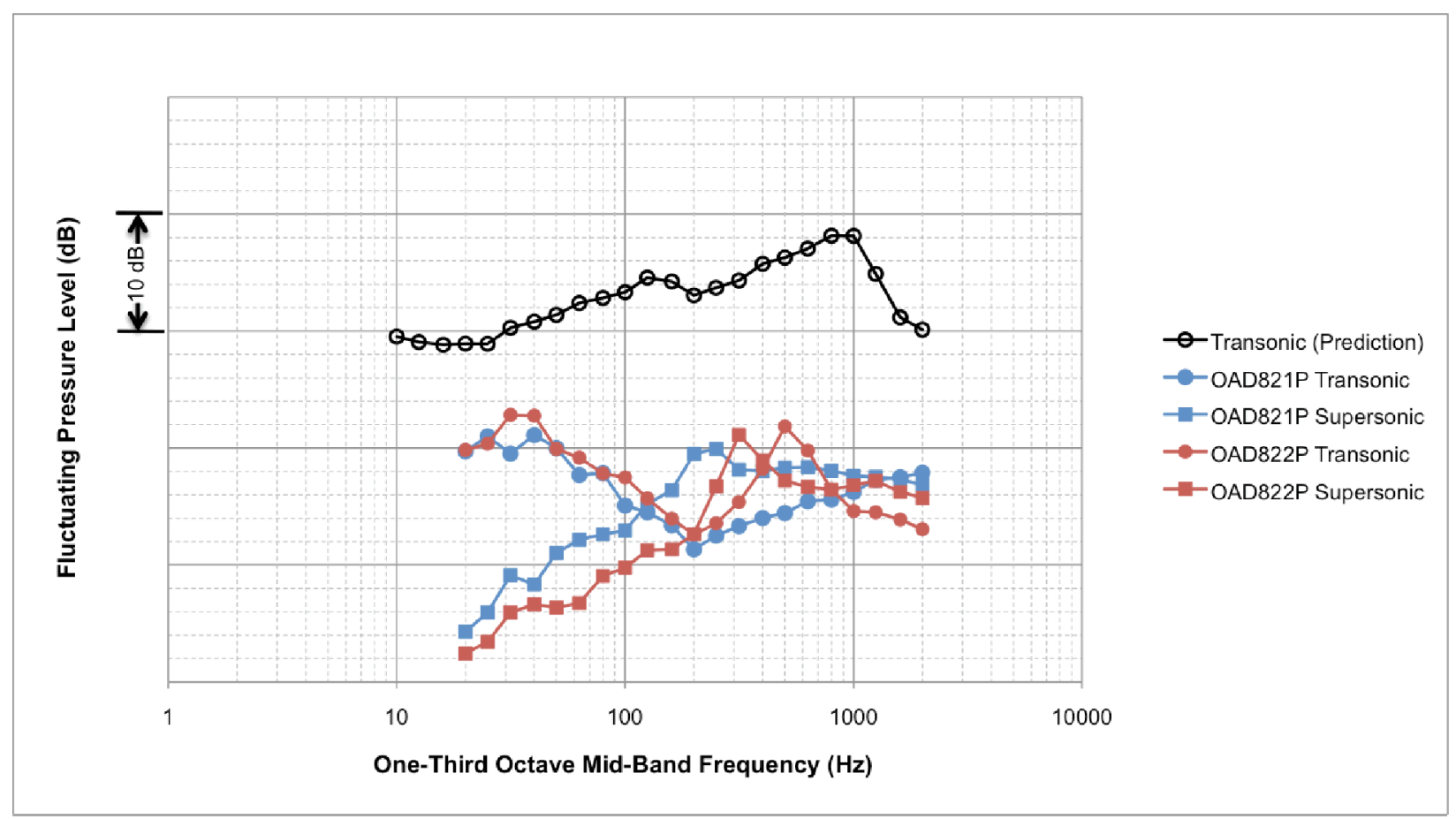

Figure 8. Transducers OAD821P and OAD822P One-Third Octave Spectra with Pre-flight Prediction 
Transducer OAD827P was located on the CM, on the forward section of the "party hat" (Figure 9).

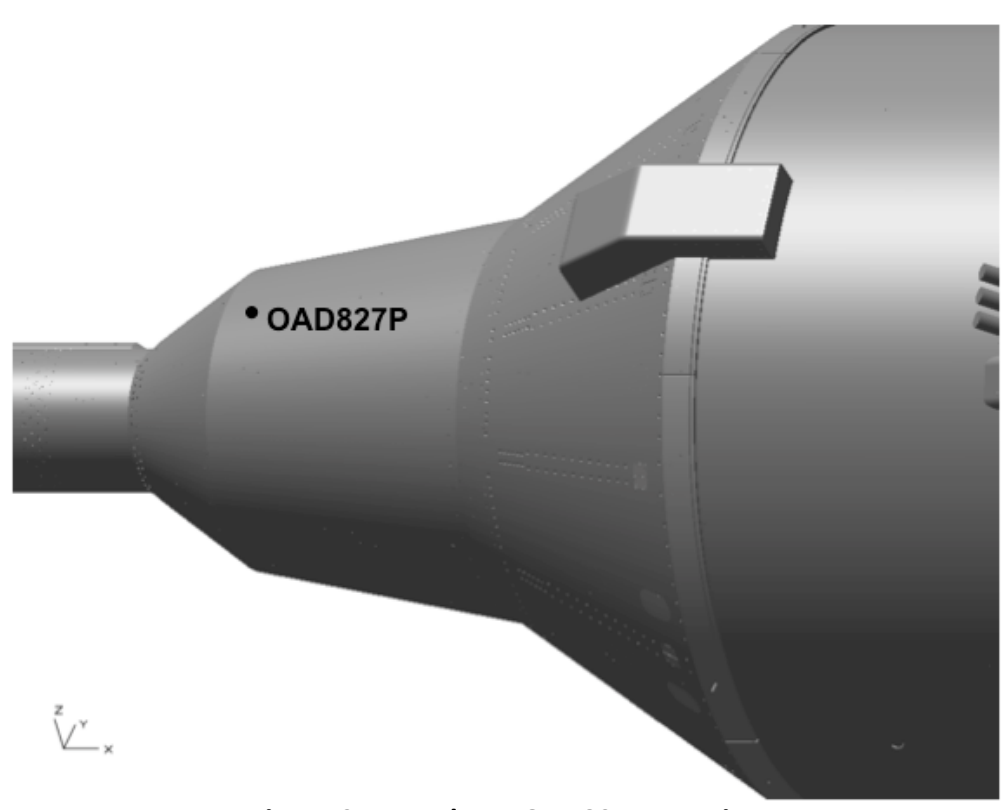

Figure 9. Transducer OAD827P Location

Transducer OAD827P and its prediction can be seen in Figure 10 below. The measured transonic data compared well with the pre-flight prediction, however the measured supersonic data exceeded them.

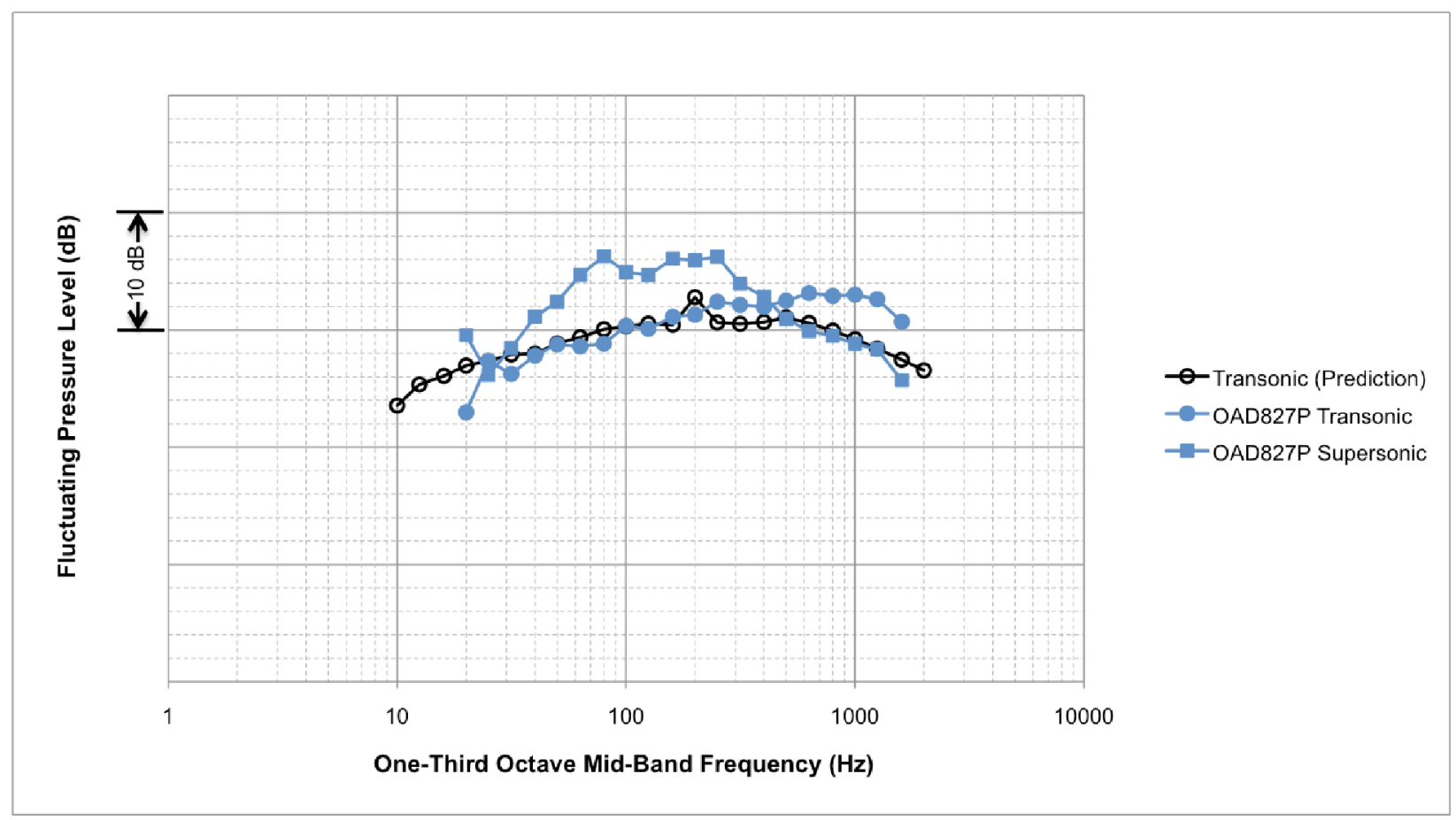

Figure 10. Transducer OAD827P One-Third Octave Spectra with Pre-flight Prediction 
Transducer IAD914P was located on the forward section of the SM, away from any major protuberances (Figure 11).

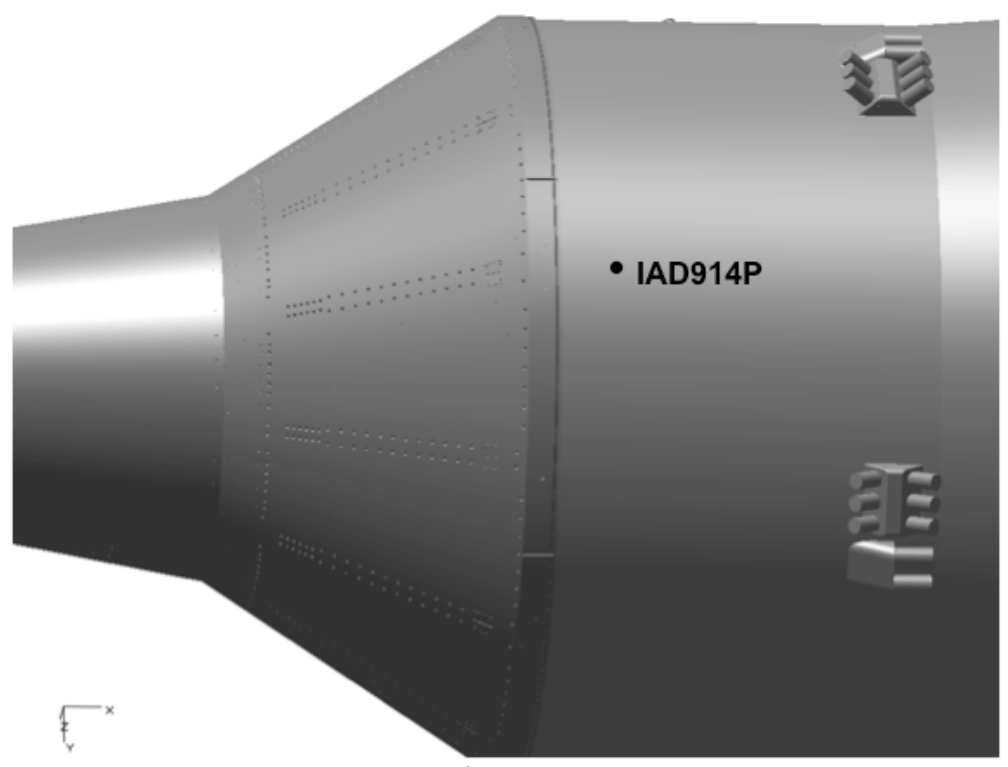

Figure 11. Transducer IAD914P Location

Transducer IAD914P and its prediction can be seen in Figure 12 below. Though its transducer location matched closely to that of a scaled model transducer, its measured data did not compare well with pre-flight predictions. The measured transonic levels were slightly greater than expected for a few mid-band frequencies, and like the measured supersonic levels at most frequencies, were less than expected at higher frequencies.

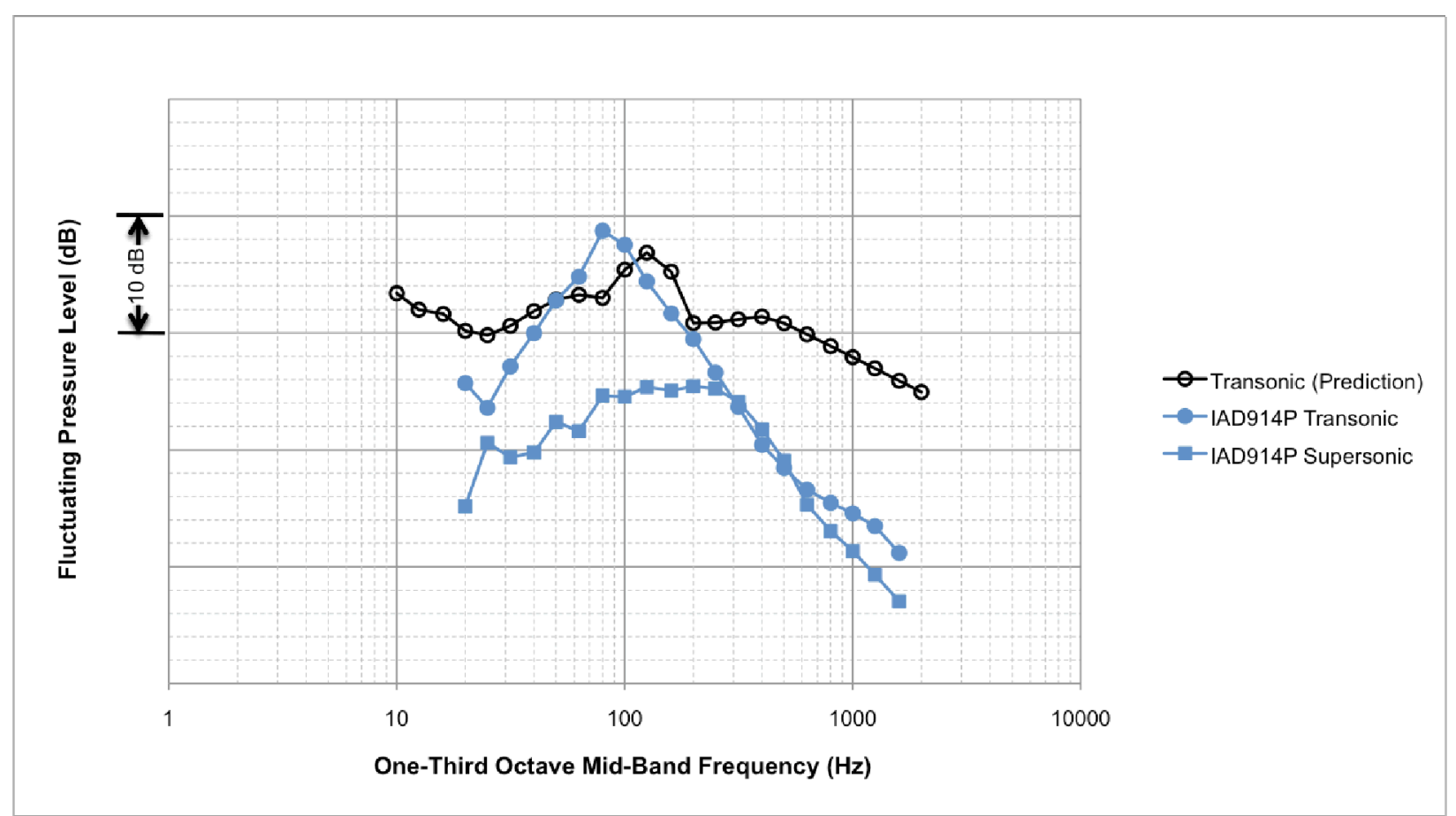

Figure 12. Transducer IAD914P One-Third Octave Spectra with Pre-flight Prediction 
Transducer IAD630P was located on the USS, away from any major protuberances (Figure 13).

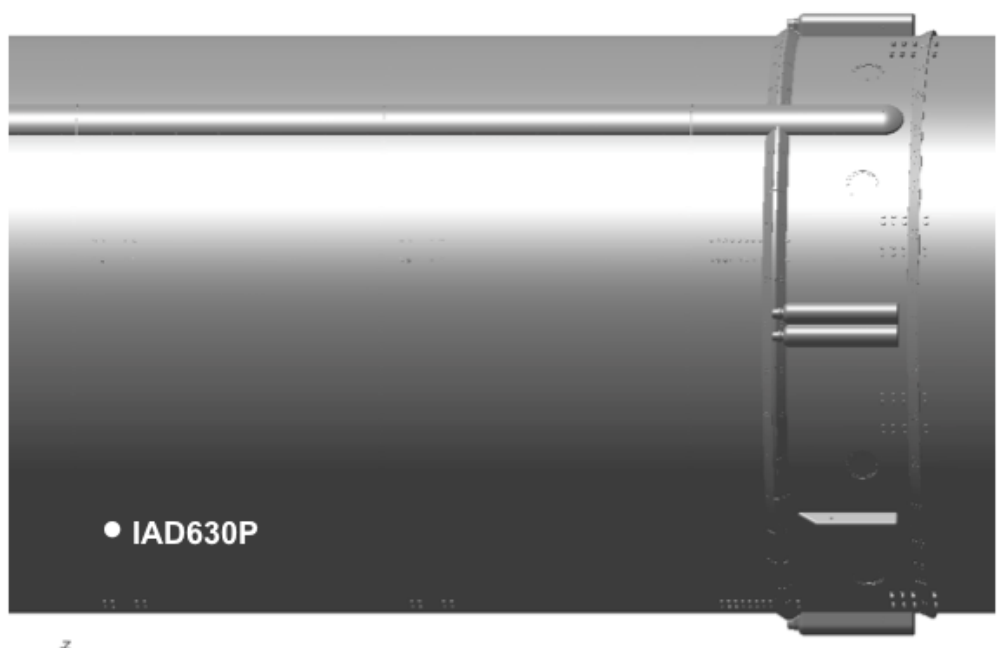

Figure 13. Transducer IAD630P Location

Transducer IAD630P and its predictions can be seen in Figure 14 below. The measured transonic data were greater than expected for all frequencies, and the measured supersonic data were greater than expected at higher frequencies and less than expected at lower frequencies.

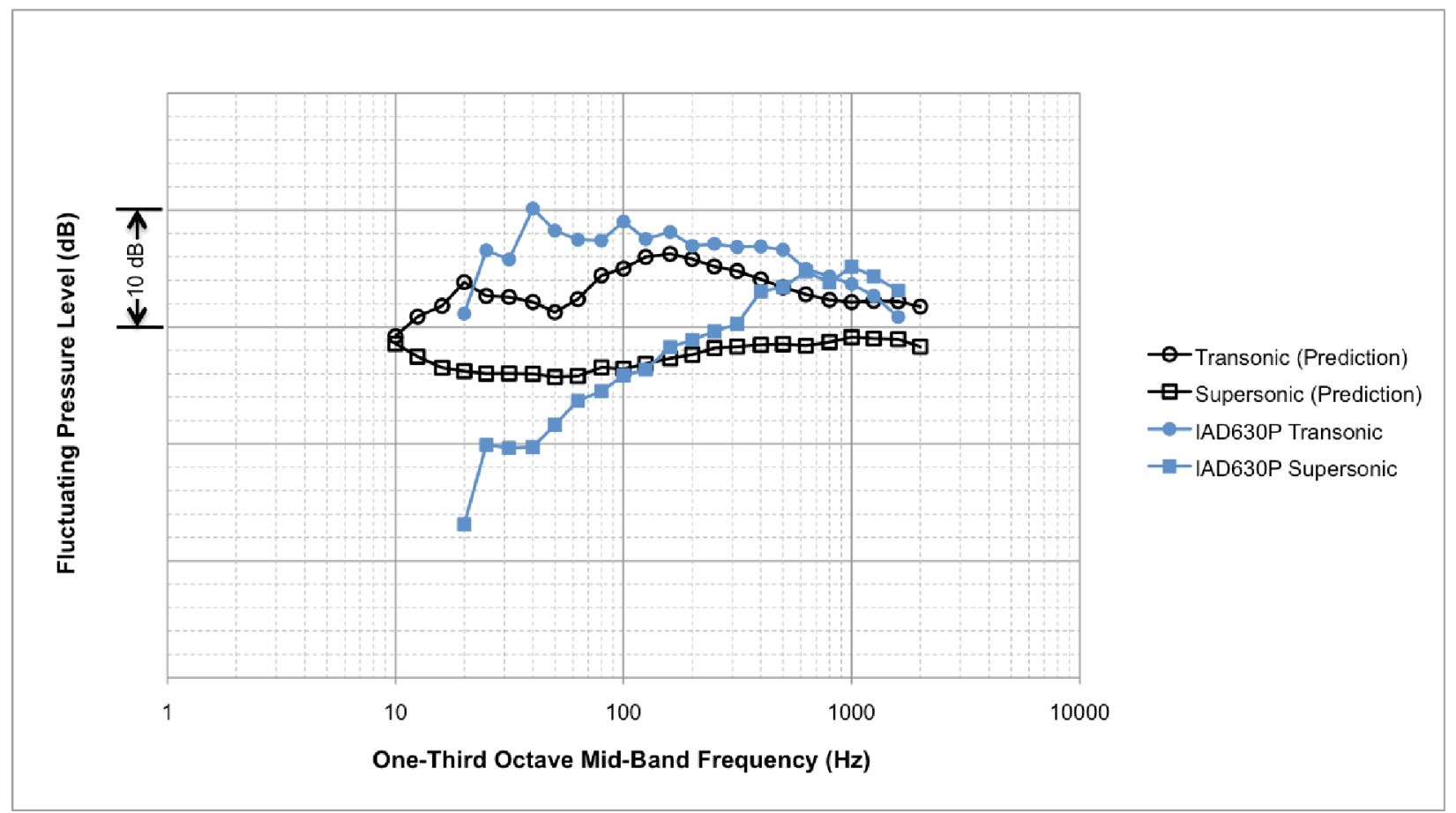

Figure 14. Transducer IAD630P One-Third Octave Spectra with Pre-flight Predictions 
Transducers IAD095P and IAD097P were located on the Interstage, Figure 15.

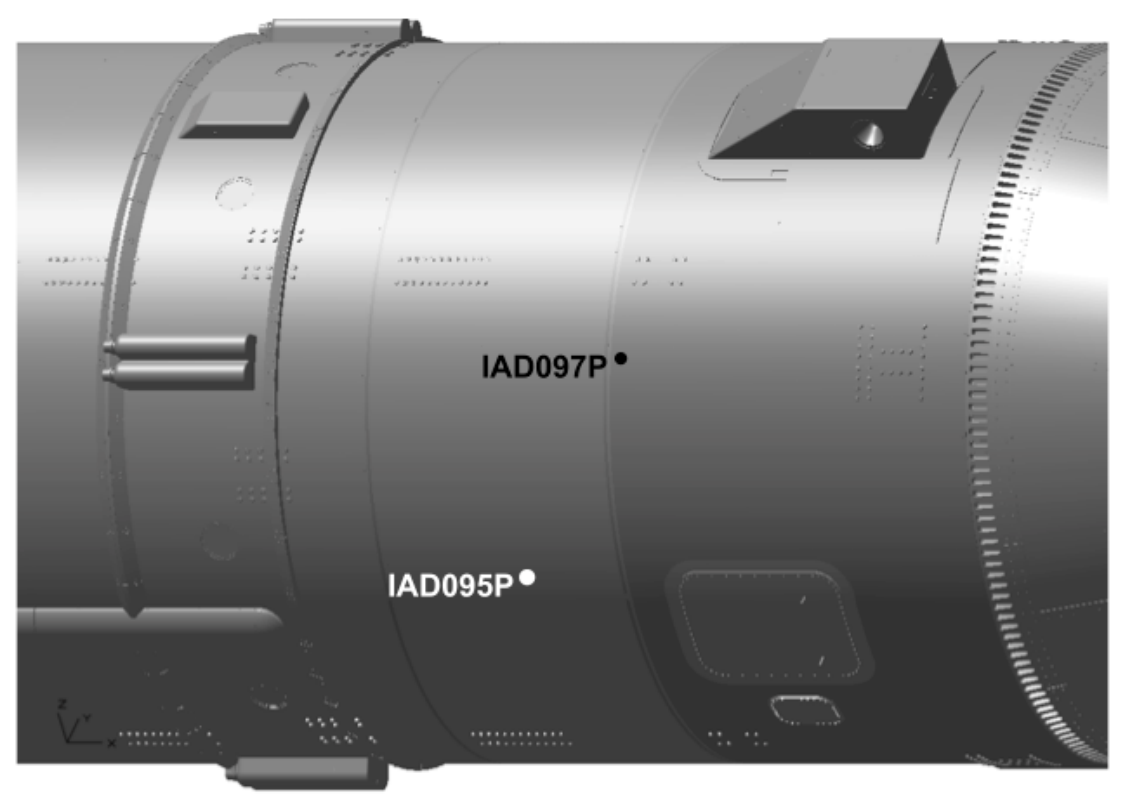

Figure 15. Transducers IAD095P and IAD097P Locations

Transducers IAD095P and IAD097P and their predictions can be seen in as seen in Figure 16 below. IAD095P's location matched closely to that of a scaled model transducer and its measured data compared well with pre-flight predictions. IAD097P's location did not match closely to that of a wind tunnel transducer, but its measured data still compared well to the predictions.

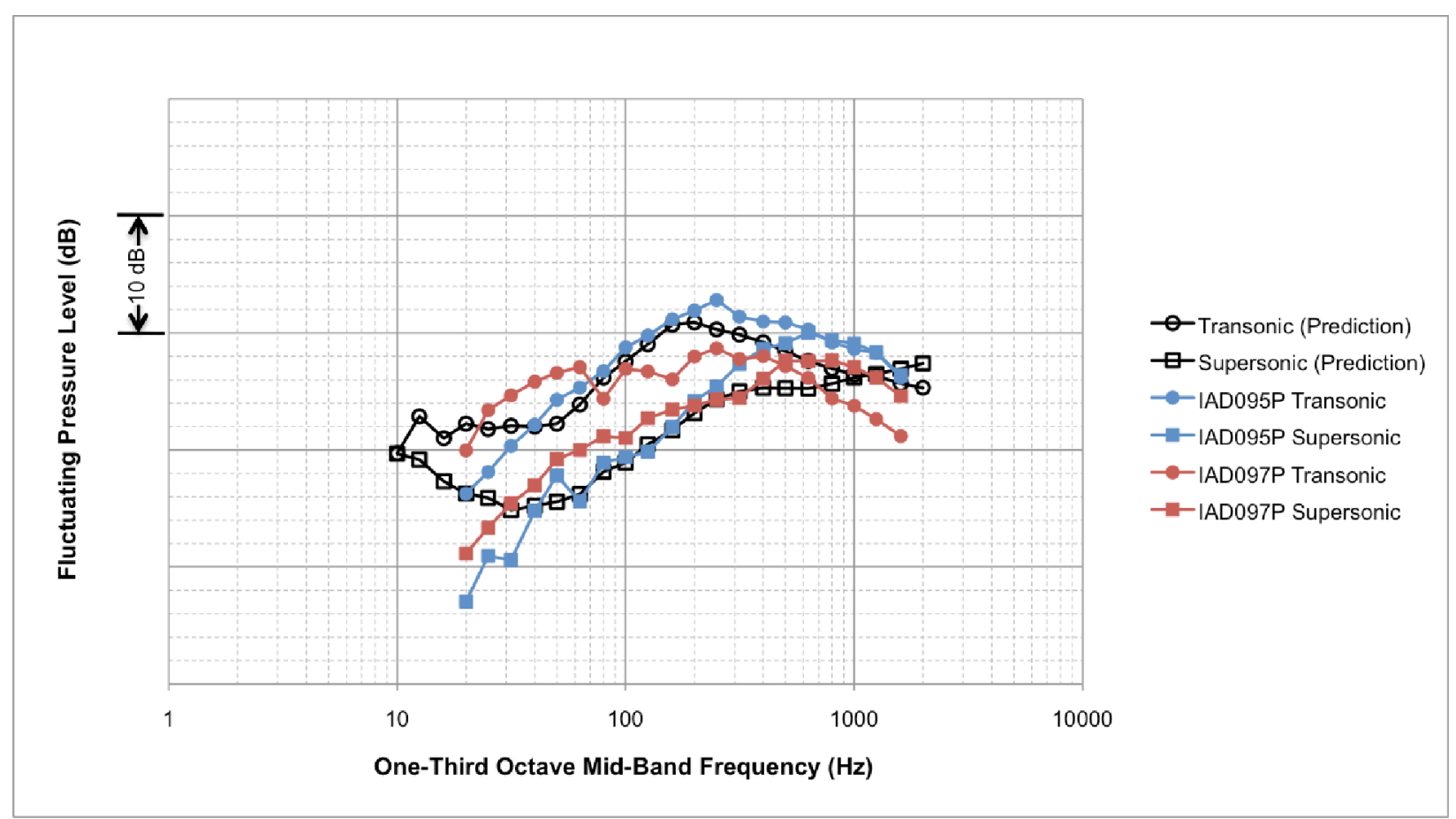

Figure 16. Transducers IAD095P and IAD097P One-Third Octave Spectra with Pre-flight Predictions 
Transducer AAD155P was located on the FS forward skirt (Figure 17. Transducer AAD155P Location).

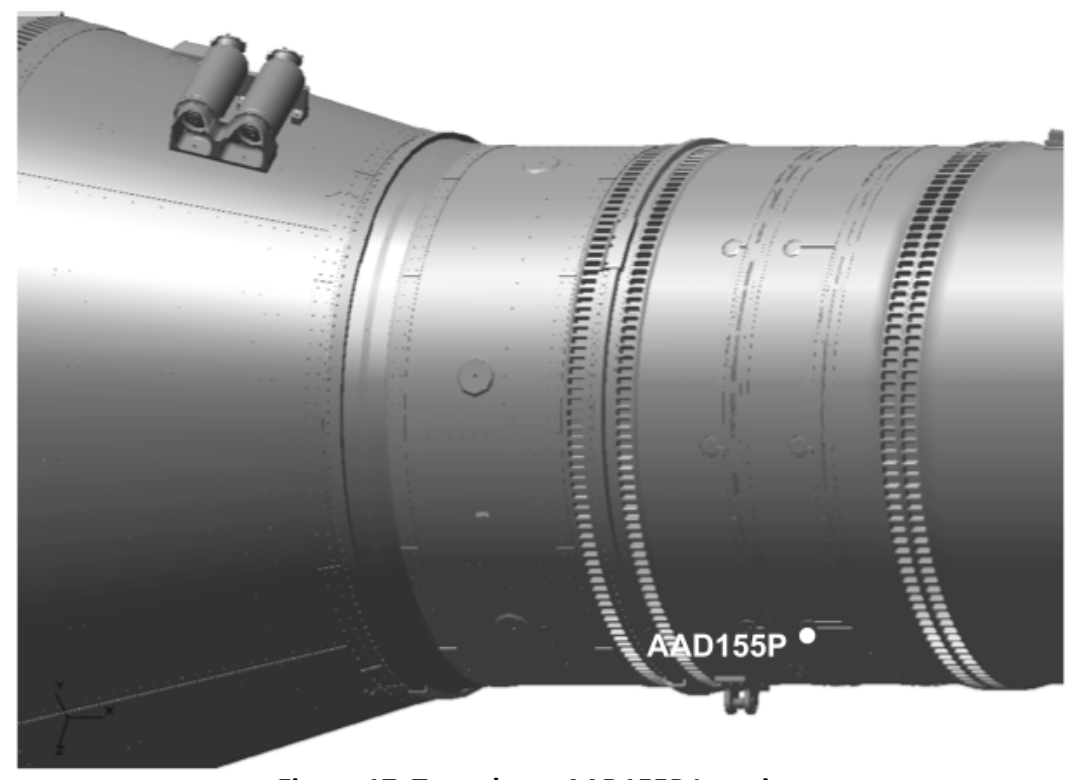

Figure 17. Transducer AAD155P Location

Transducer AAD155P and its predictions can be seen in Figure 18 below. The measured transonic levels compared reasonably well to the pre-flight transonic predictions, especially at the higher frequencies, however the measured supersonic levels exceeded their predictions for all frequencies.

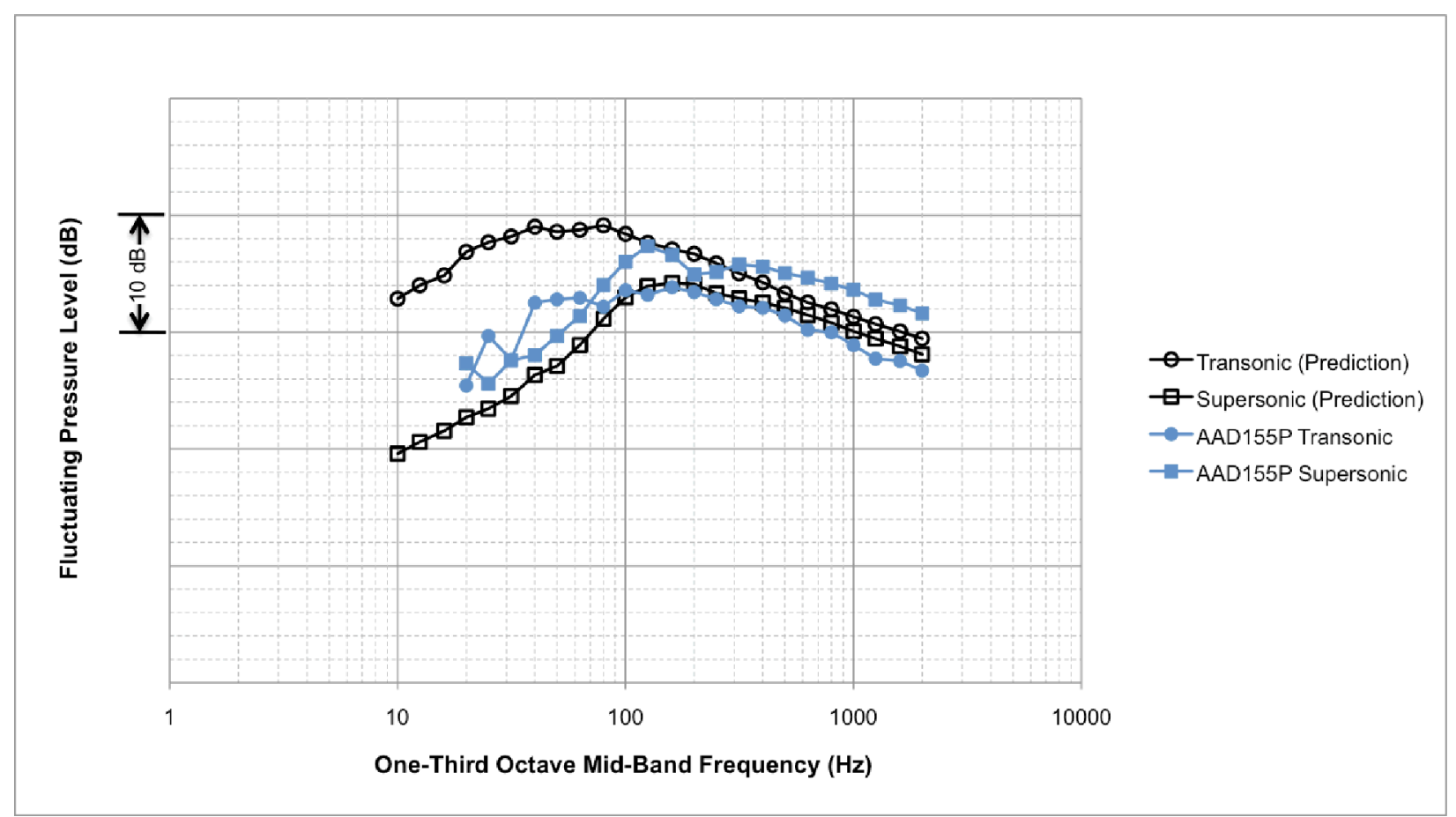

Figure 18. Transducer AAD155P One-Third Octave Spectra with Pre-flight Predictions 
Transducer AAD159P was located on the FS aft skirt (Figure 19).

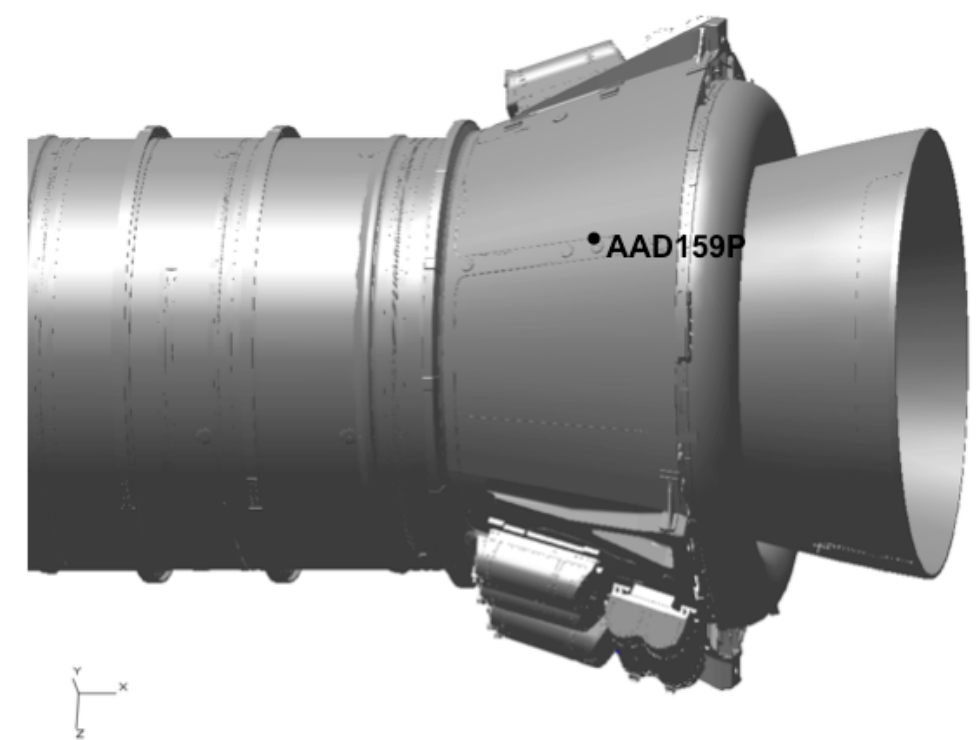

Figure 19. Transducer AAD159P Location

Transducer AAD159P and its prediction can be seen in Figure 20 below. Its measured transonic data compared very well with the predictions, but the measured supersonic data exceeded them.

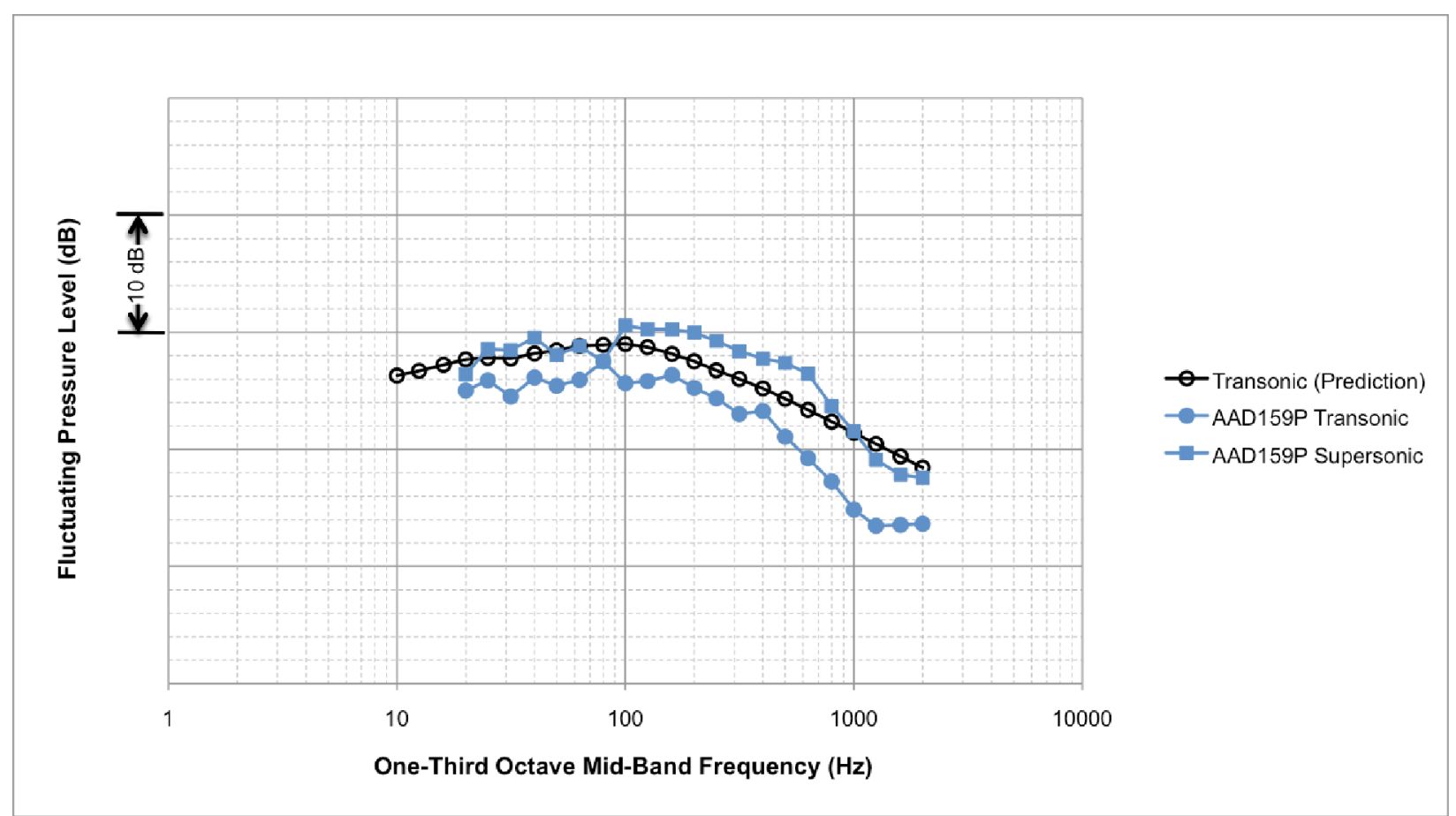

Figure 20. Transducer AAD159P One-Third Octave Spectra with Pre-flight Prediction 


\section{Conclusions/Recommendations}

Aeroacoustic flight data were measured at 57 locations along the Ares I-X flight test vehicle. Several of these transducers were placed to duplicate those utilized on either the TDT-599 Ares I-X FTV sub-scale model or the AIISA001 Ares I CLV sub-scale model. For these measurements, data gathered during the wind tunnel tests and data gathered during the ascent phase of the flight test were compared. These comparisons were made with closely matching flight conditions (Mach number) in order to preserve a one-to-one relationship. In general, where flight and wind tunnel transducers matched locations, the transonic flight measurements compared well with the preflight predictions. Flight measurements near protuberances and supersonic flight measurements did not compare well with the wind tunnel test data.

One important observation made when comparing these measurements was the discrepancies in flight environments and predicted environments near changes in outer mold line geometries. In general, measurements near major outer mold line changes and/or protuberances, especially whose locations do not closely match any on a sub-scale wind tunnel model, do not compare well with pre-flight predictions. This is due to the complexity and wide fluctuations in the flow fields produced by variations in the vehicle's geometry. This can be seen best by transducers OAD821P and OAD822P (Figure 8), whose environments contrasted greatly from the predictions. This may also explain the difference between IAD914P (Figure 12) and its prediction, though its location matched that of a wind tunnel measurement exactly. This, however, does not explain any discrepancies in zonal environments, where measurements were located away from any protuberances, as seen in IAD630P (Figure 14). Zonal environments should agree very well with predictions, similar to transonic AAD155P (Figure 18), transonic AAD159P (Figure 20), IAD095P, and even IAD097P (Figure 16), though its location did not closely match one on a sub-scale model.

A second important observation made was the dramatic under-prediction of the supersonic environments. Several supersonic flight aeroacoustic measurements were much greater than expected. This can be seen by transducers OAD819P (Figure 7), OAD827P (Figure 10), AAD155P (Figure 18), AAD159P (Figure 20) and others. Typically, transonic predictions envelop supersonic predictions and influence vehicle design, however many of the actual supersonic environments exceeded the transonic predictions. This phenomenon may be configurationspecific, or may be an inherent flaw in the scaling methodology. Further investigation is necessary.

\section{References}

${ }^{1}$ Piatak, D. J., Florance, J. P., Ivanco, T. G., Rausch, R. D., Sekula, M. K., and Wiesman C. D., Test Summary Document for the 3.5 Percent Ares I-X Rigid Buffet/Aeroacoustic Model in the Transonic Dynamics Tunnel, NASA LaRC Aeroelasticity Branch, ARES-AE-TA-0002, January 31, 2008.

${ }^{2}$ Hamilton, C. R., Mayle, M. N., Crosby, W. A., Nance, D. K., and Reed, D. K., Ascent Acoustics Test of a 4\%-Scale Ares I Model in the NASA Ames Research Center Unitary Plan Wind Tunnels, ESTSG-FY09-00450, February 2009. 
An Assessment of Ares I-X Aeroacoustic Measurements with Comparisons to Pre-Flight Wind Tunnel Test Results

\author{
Darren K. Reed \\ NASA / MSFC \\ Melody N. Mayle \\ NASA / MSFC
}

Don Nance

Georgia Tech Research Institute

49 ${ }^{\text {th }}$ AIAA Aerospace Sciences Meeting

4-7 January 2011 


\section{Outline}

- Objective

- Ares I Program

- Ares I-X Flight Test Vehicle

- Wind Tunnel Test Programs

- Ares I-X Aero Buffet Test, TDT 599, at LaRC

- Ares I Aeroacoustic Test at ARC

- Data Processing and Scaling

- Ares I-X Flight Data

- Wind Tunnel Test Data

- Flight to Wind Tunnel Comparisons

- Conclusions 


\section{Objective}

- Aeroacoustic measurements from the Ares I-X Flight Test Vehicle were compared to similar measurements on two different wind tunnel tests

- In general, flight measurements are used to validate wind tunnel test developed environments 


\section{Ares I Project}

- Ares I vehicle was designed to carry the Orion crewed capsule to the International Space Station and other low Earth orbit missions

- The Ares I vehicle consisted of three primary stacked elements: the CEV/LAS, the Upper Stage, and the First Stage

- CEV/LAS - Crew Exploration Vehicle and Launch Abort System consists of the crew capsule, the extended service module, and the launch abort system

- Upper Stage - Instrumentation Unit,Liquid Hydrogen Tank, Liquid Oxygen Tank, J2-X upper stage engine, Interstage

- First Stage - frustum, forward skirt extension, forward, skirt, a five segment solid rocket motor, aft skirt, similar to the Space Shuttle four segment solid rocket boosters 


\section{Ares I-X Flight Vehicle}

- Ares I-X is a full scale Ares I test flight vehicle

- Primary objectives of the Ares I-X was to determine the overall vehicle dynamics and its buffet response and the handling, stacking, and ground processing operations

- One secondary objective was to acquire flight environments to validate the various models and test simulations

- Ares I-X configuration - stackable segments were built to simulate the outer mold line of the Ares I and to simulate the general mass characteristics.

- The CM/LAS and Upper Stage segments were thick steel-walled simulators

- No second or third stage motors

- Only the first stage motor was real, but only four solid rocket segements - the fifth stage was used for ballast and contained the GNC and data acquisition system 


\section{Outer Mold Line Comparison}

\section{Ares I Flight Configuration}

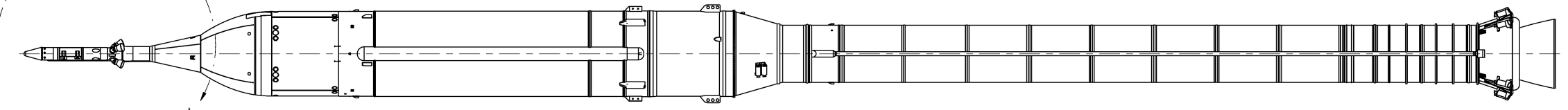

The main difference between the flight test vehicle and the Ares I was the addition of the ogive fairing to the $\mathrm{CM}$ and the increased diameter of the service module

\section{Ares I-X Flight Test Vehicle}

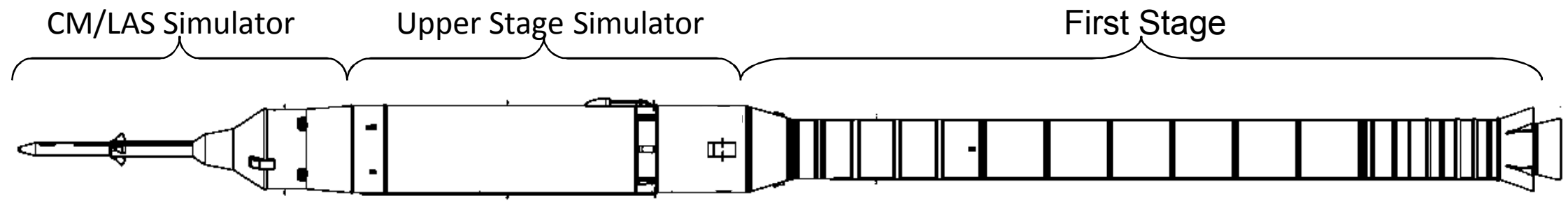




\section{Ares I-X Transducer Layout}

- 26 Transducers on the CM/LAS

- 22 Transducers on the Upper Stage

- 9 Transducers on the First Stage

- Total of 57 gages

- All aeroacoustic transducers were high pass filtered to eliminate static pressure changes

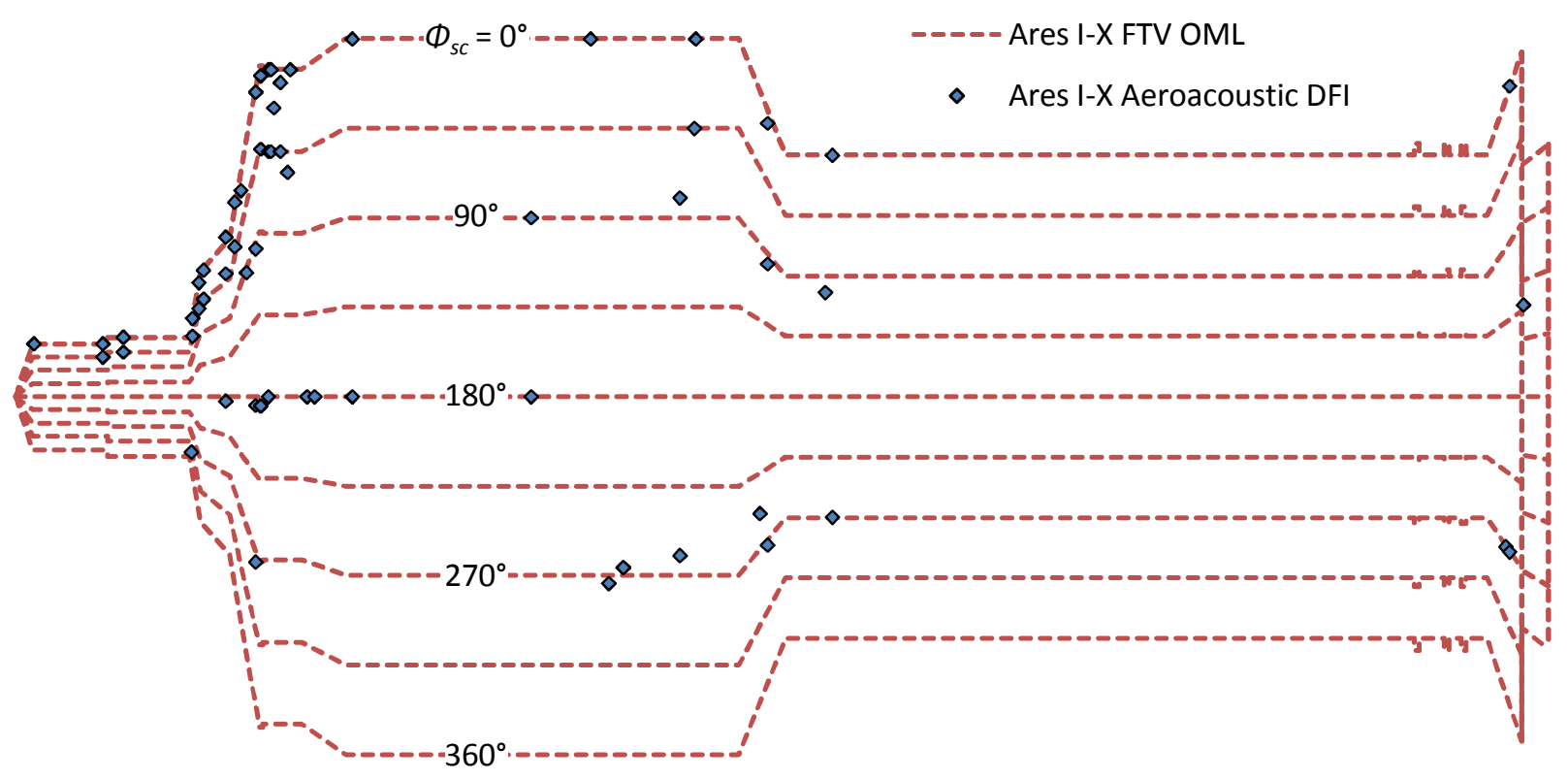




\section{Typical Fluctuating Pressure Transducer Installations}

FS fwd skirt transducer installed within an exterior mounted fairing

FS aft skirt transducer installed within an exterior mounted fairing

\section{(1)}

AAD159P

(9)

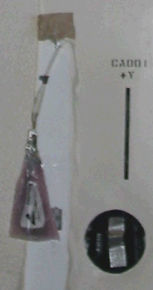




\section{Ares I-X Aerobuffet Wind Tunnel Test}

- $3.5 \%$ subscale full-stack model with the Ares I-X FTV outer mold line configuration

- 32 aeroacoustic measurements were added to gain data for this configuration

- Data used to compare to aeroacoustic wind tunnel test

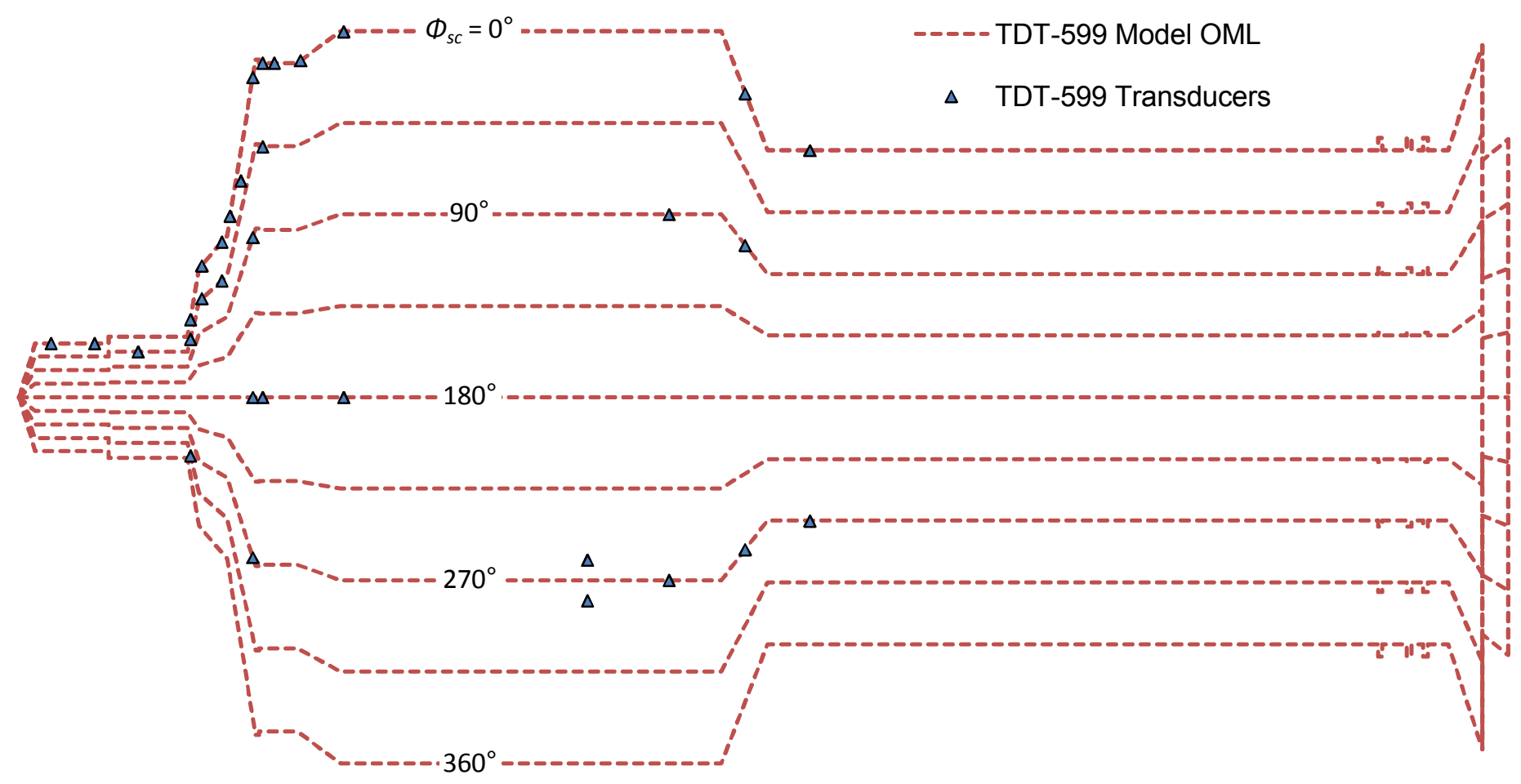




\section{Ares I Aeroacoustic Wind Tunnel Test}

- $4 \%$ subscale model truncated near the fifth motor segment

- 150 fluctuating pressure transducers

- Tested at ARC's 11 foot and 9x7 foot Unitary Wind Tunnels

$0.5 \leq$ Mach $\leq 2.5 \quad-7^{\circ} \leq \alpha \leq+7^{\circ} \quad-7^{\circ} \leq \beta \leq+7^{\circ}$

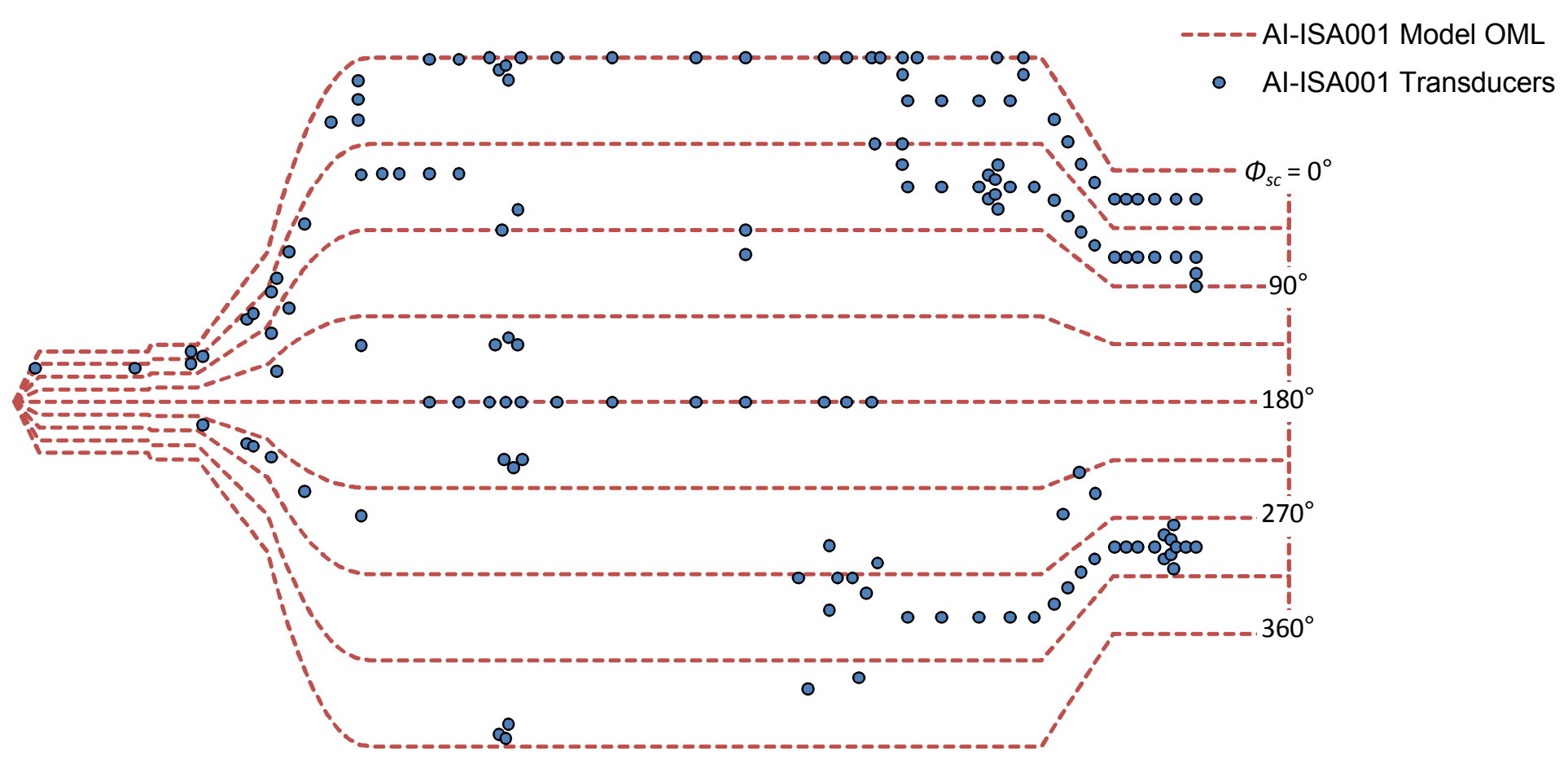




\section{Ares I Aeroacoustic Model in ARC Tunnels}

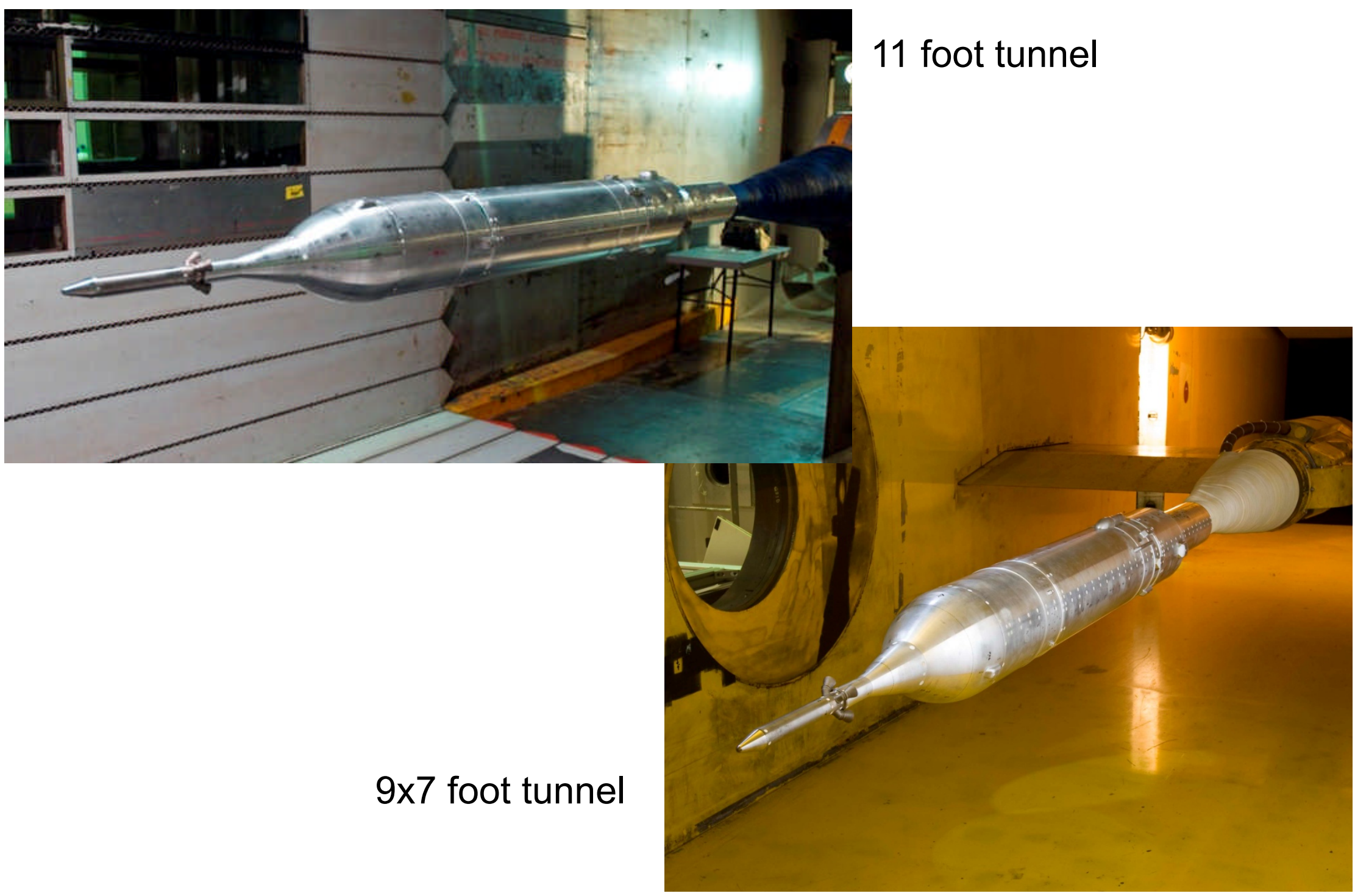




\section{Data Processing}

- Flight Data

- Fluctuating pressure data sampled at either $5.2 \mathrm{kHz}$ or $10.4 \mathrm{kHz}$

- Two second time slices were used to make the $1 / 3$ octave spectra and was associated with the appropriate flight conditions

- Wind Tunnel Data

- Fluctuating pressure data was converted to $1 / 3$ octave spectra

- Amplitude was scaled by dynamic pressure ratios to full scale

- Frequency was Strouhal scaled to full scale

$$
\begin{aligned}
& F P L_{\text {full-scale }}=F P L_{\text {sub-scale }}+20 \log _{10}\left(\frac{q_{\text {flight }}}{q_{\text {tunnel }}}\right) \mathrm{dB} \text {, re } 20 \mu \mathrm{Pa} \\
& f_{\text {full-scale }}=f_{\text {sub-scale }}\left(\frac{D_{\text {tunnel }}}{D_{\text {flight }}}\right)\left(\frac{\left(U_{\infty}\right)_{\text {flight }}}{\left(U_{\infty}\right)_{\text {tunnel }}}\right)
\end{aligned}
$$




\section{upstream of abort motor nozzles}

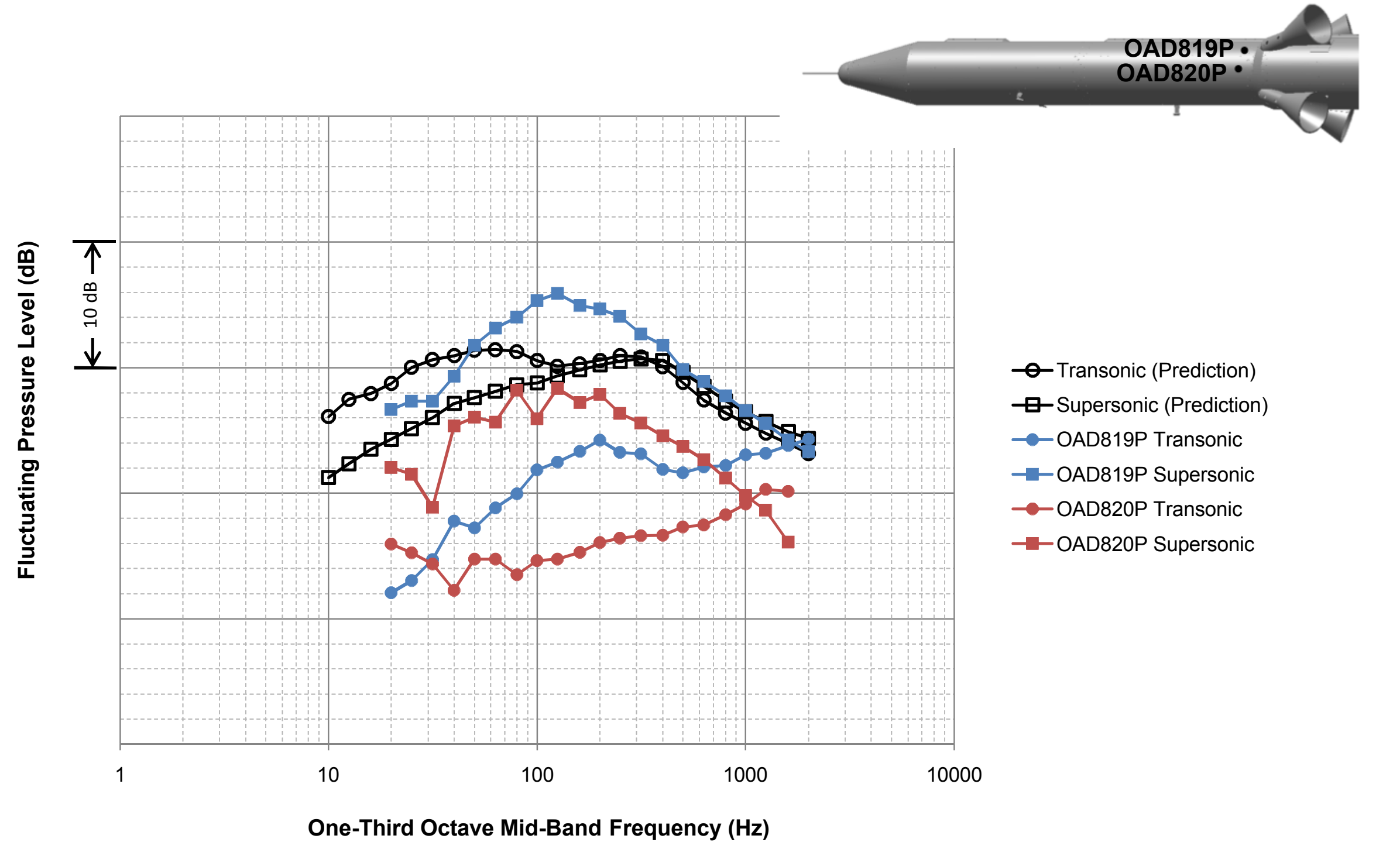




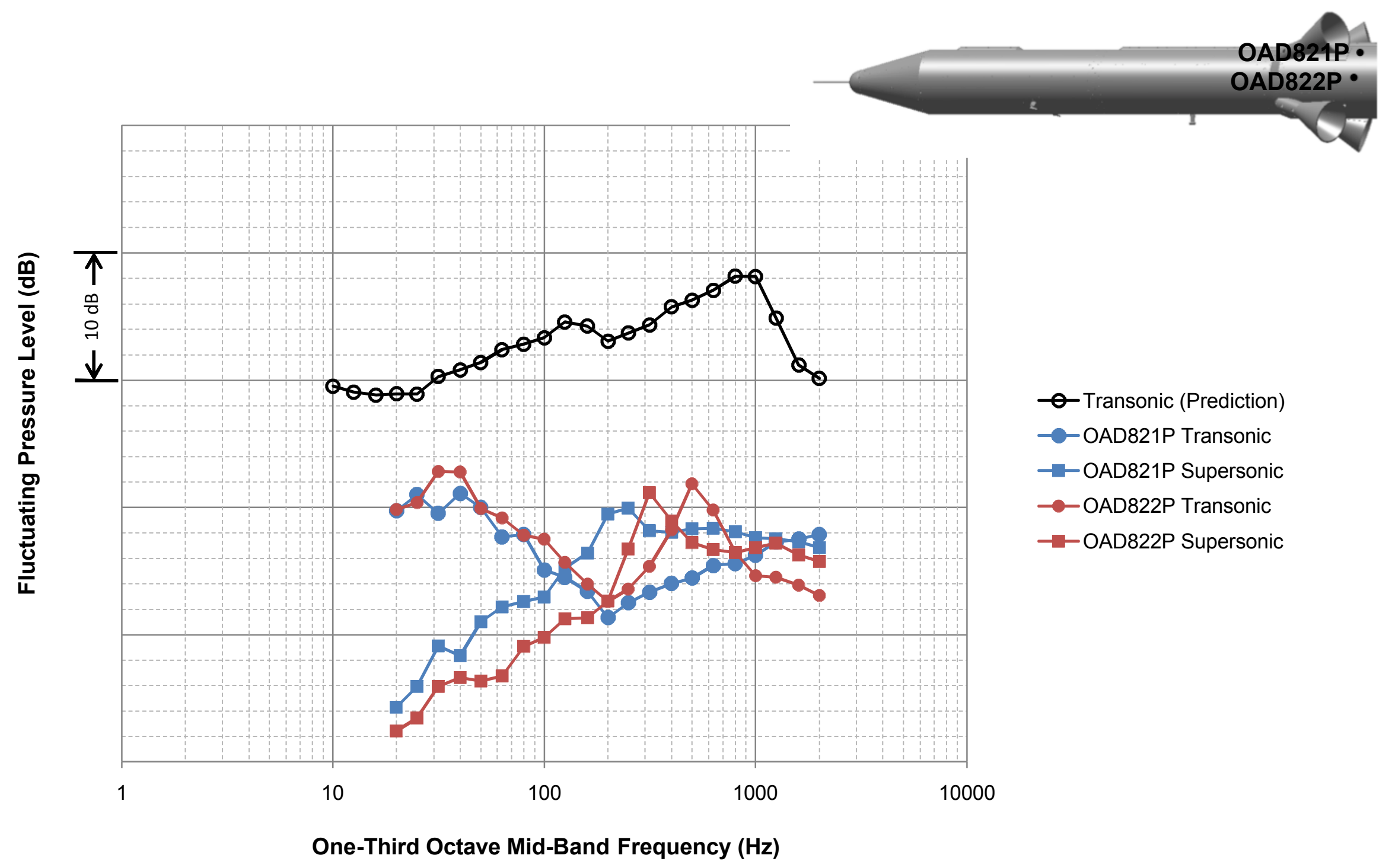




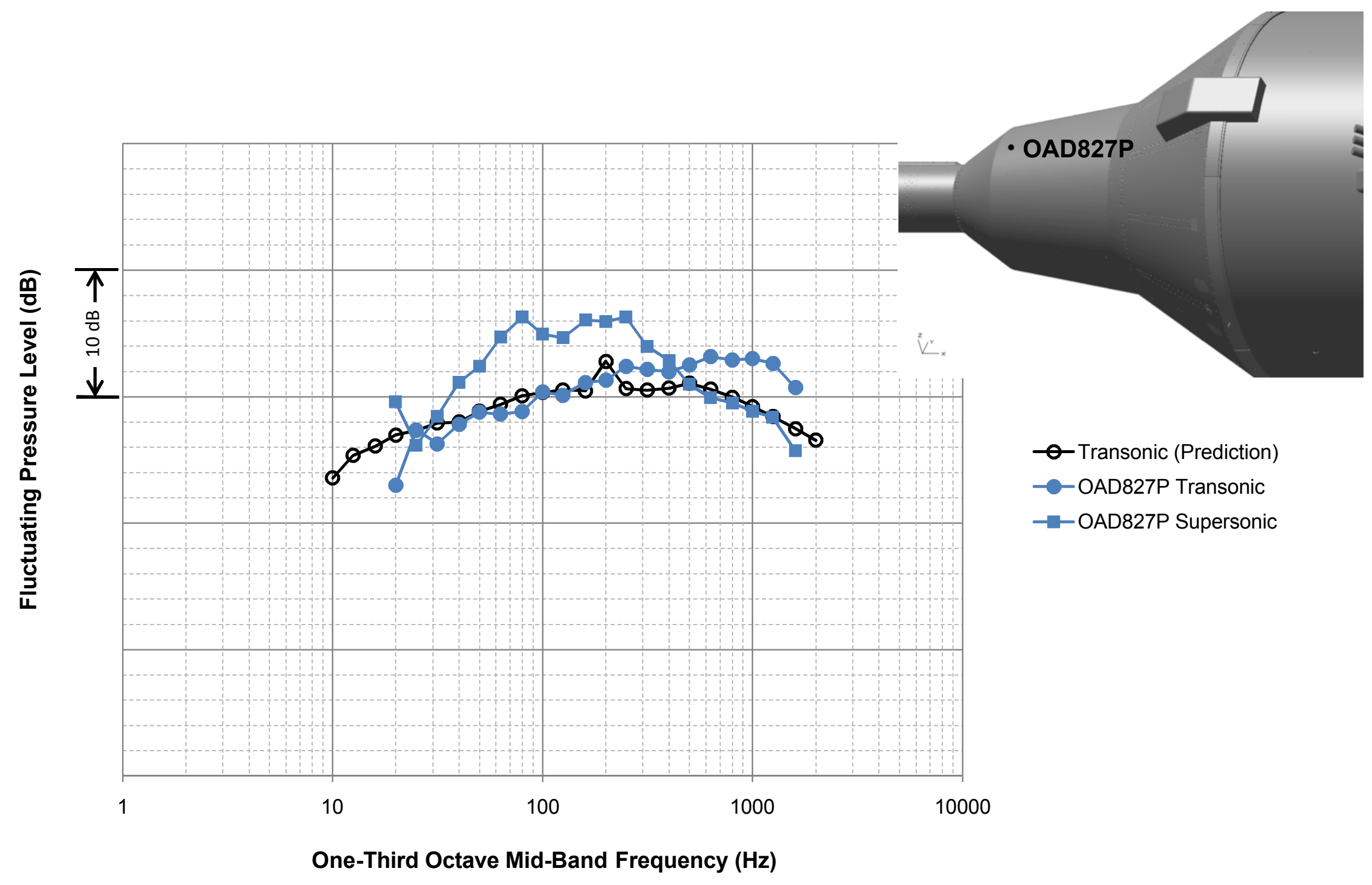




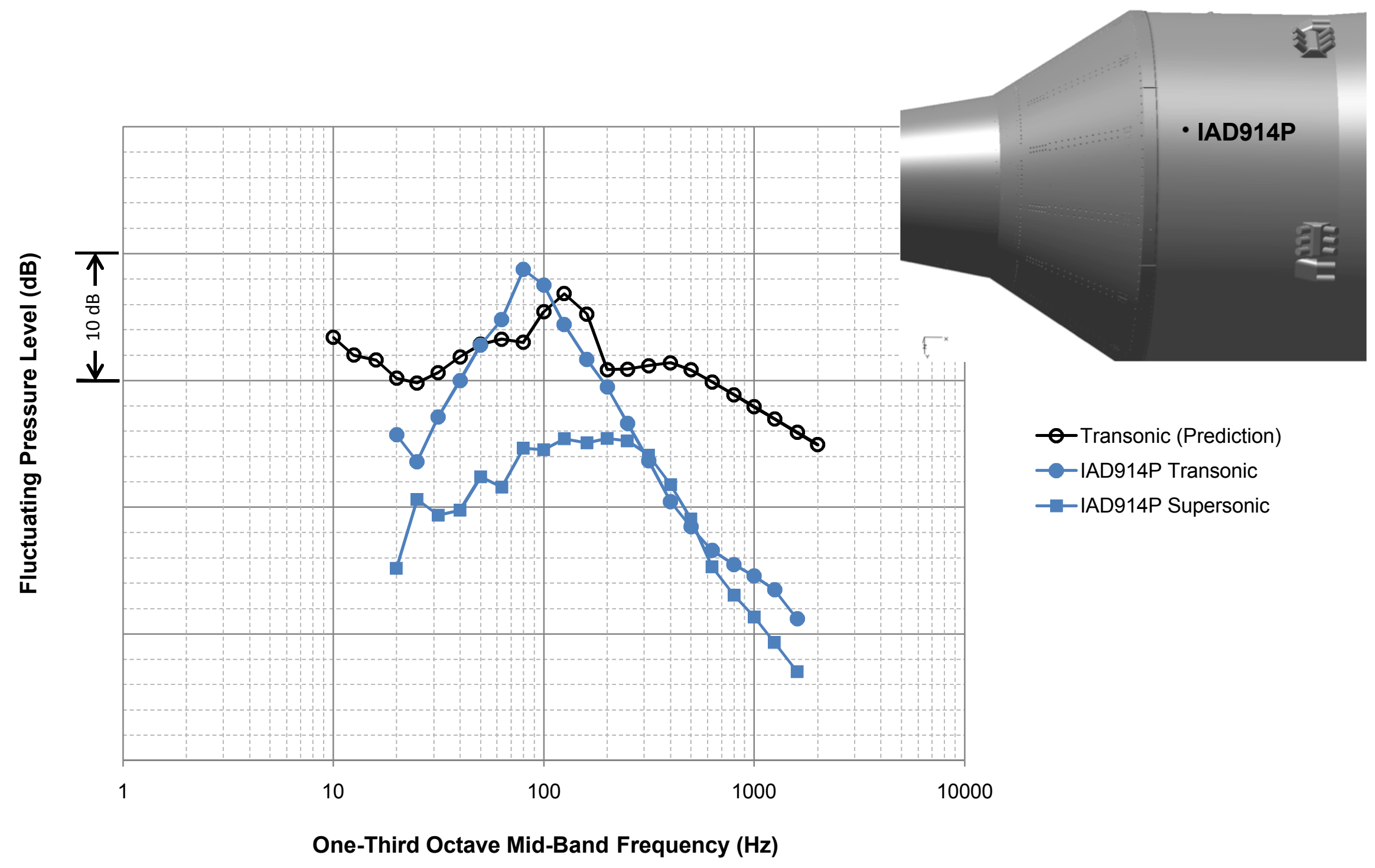



middle of $\mathrm{LH}_{2}$ tank - Upper Stage

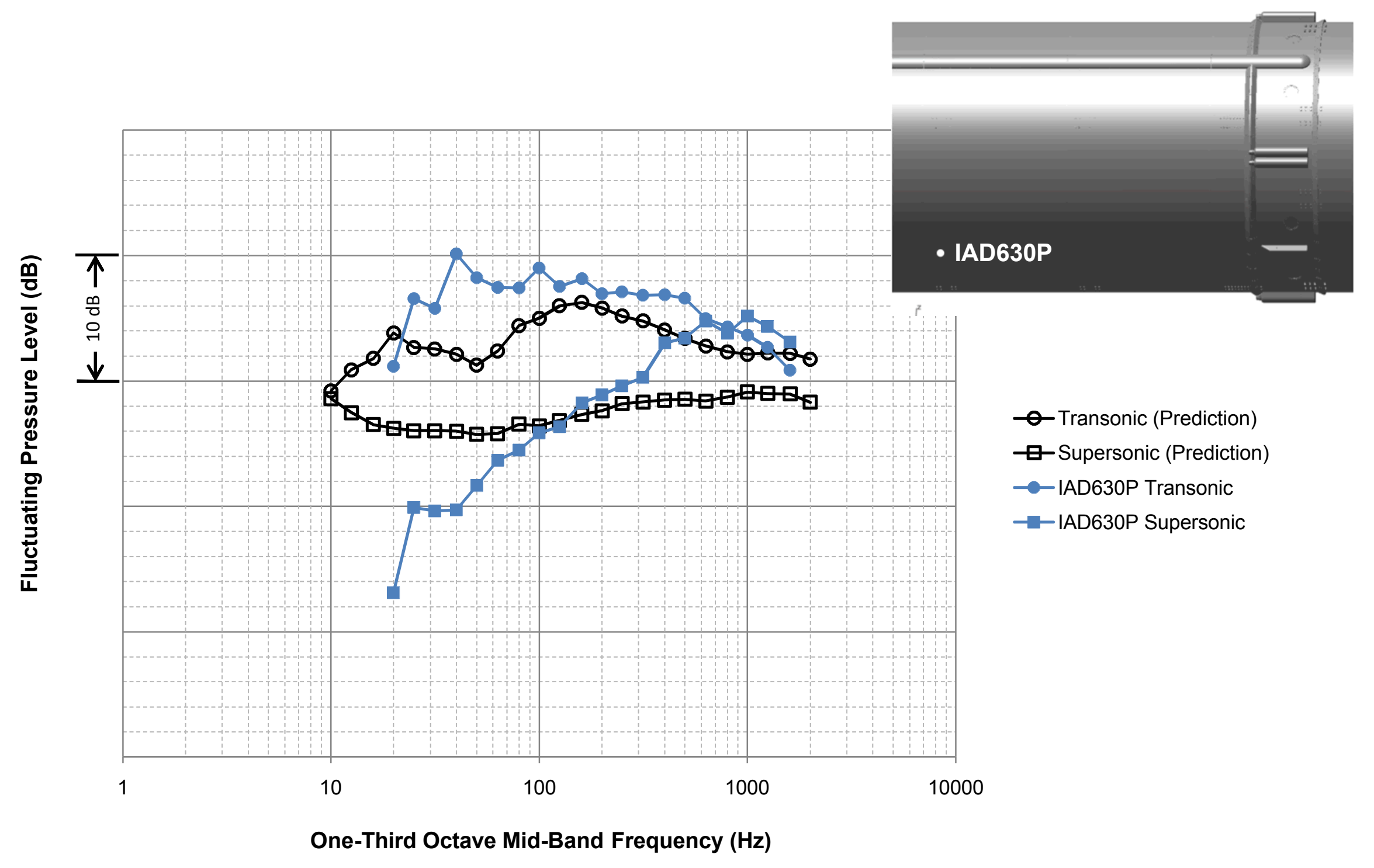




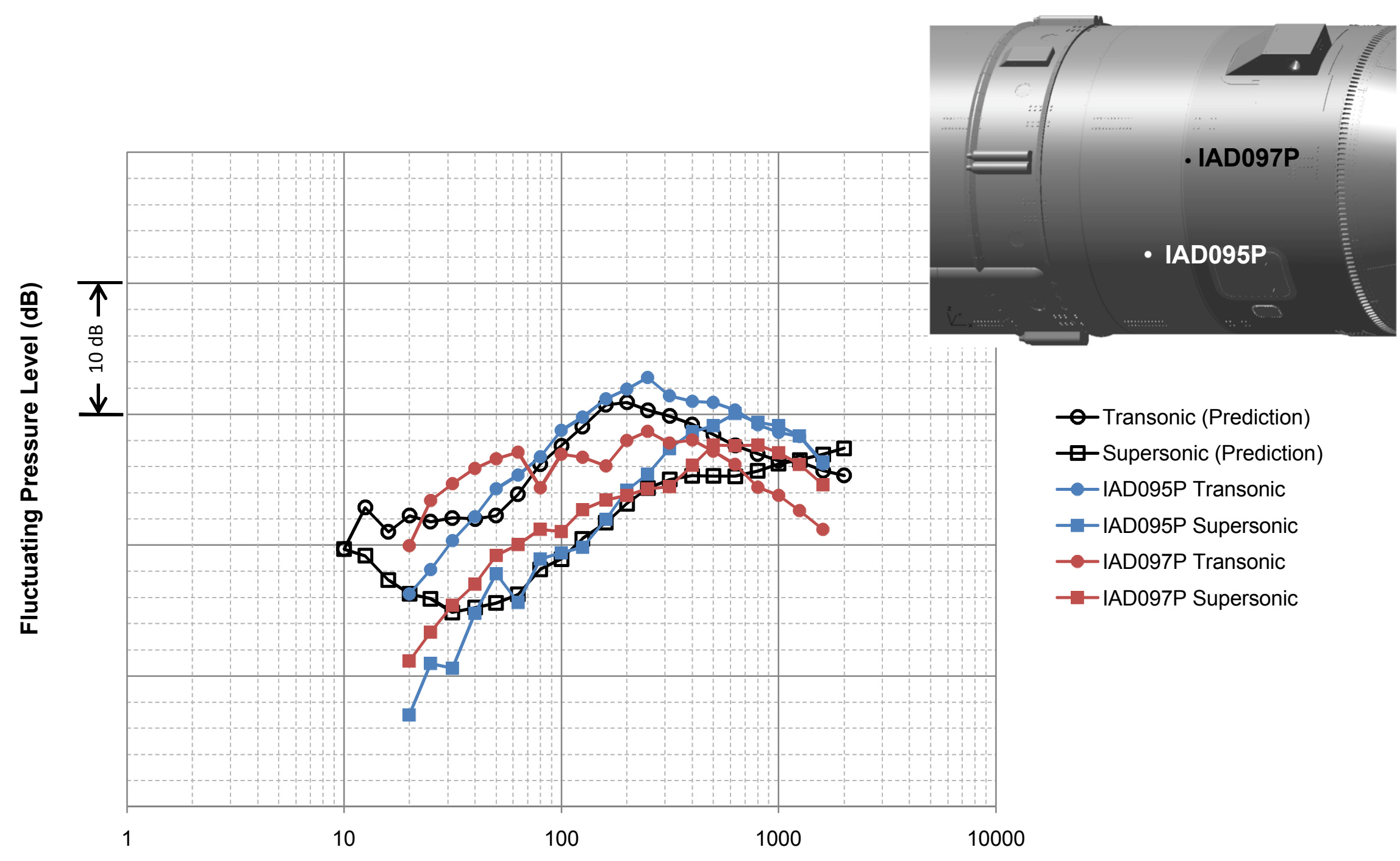

One-Third Octave Mid-Band Frequency (Hz) 


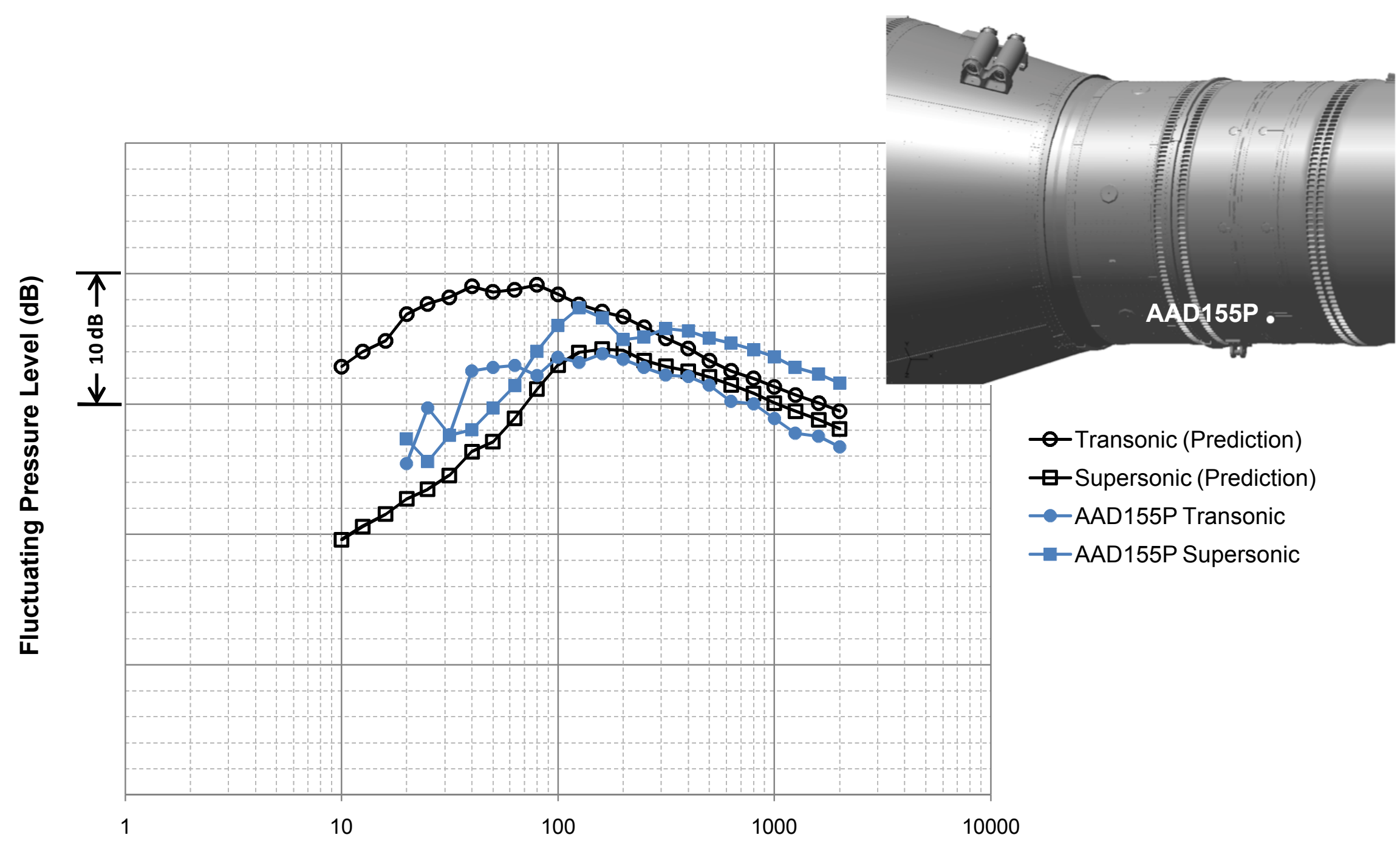

One-Third Octave Mid-Band Frequency $(\mathrm{Hz})$ 


\section{Comparison between Flight and Test}

Aft Skirt Non-protuberance area zone

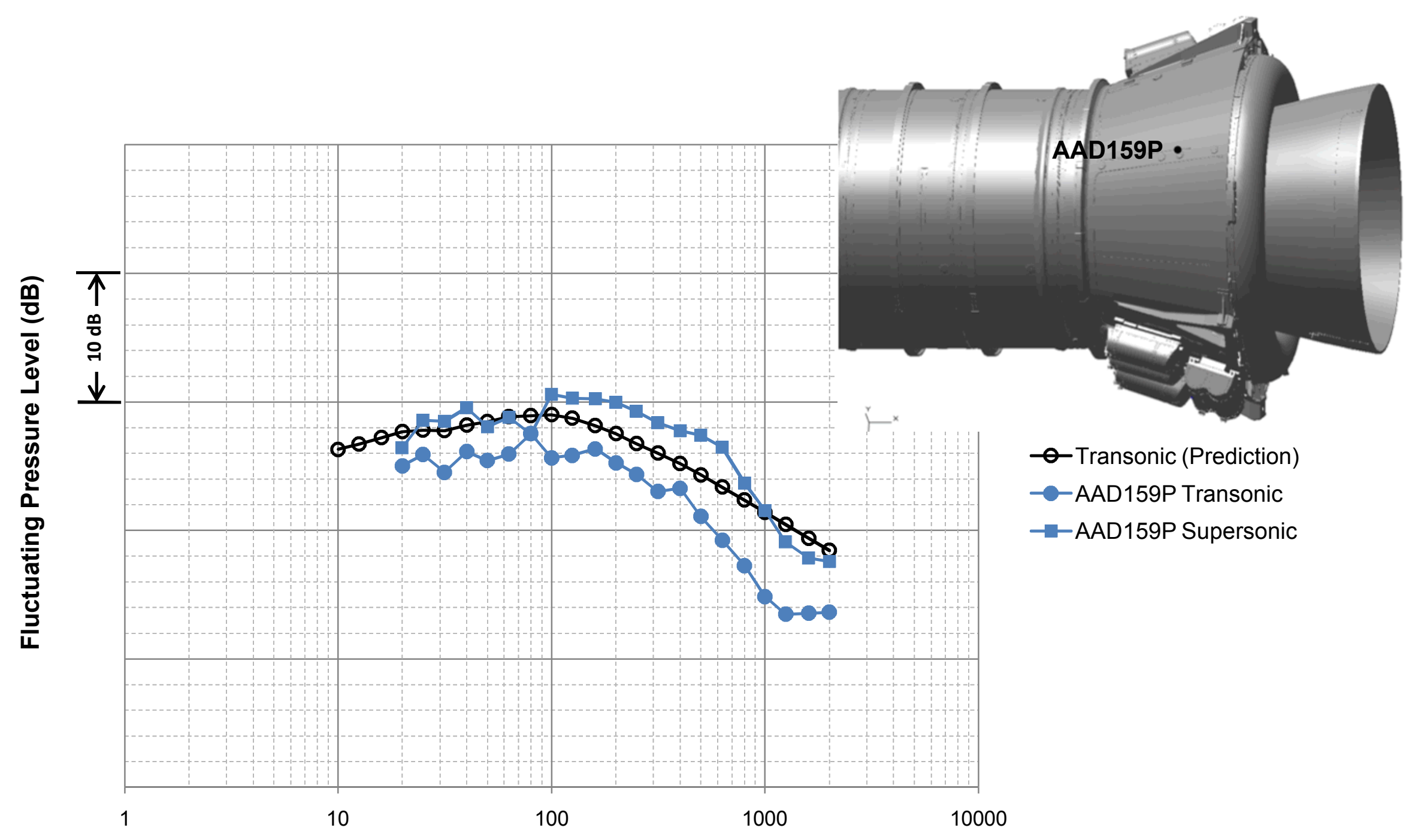

One-Third Octave Mid-Band Frequency $(\mathrm{Hz})$ 


\section{Conclusions}

- 57 Aeroacoustic transducers were recorded on the Ares I-X Flight Test Vehicle

- Many of the Ares I-X transducer locations were duplicated on two different wind tunnel tests

- Spectra from flight transducers that closely matches wind tunnel model locations generally compare well for transonic conditions

- Measurements in zonal areas (away from protuberances) generally match well with wind tunnel tests

- Flight transducers that are not closely duplicated on the wind tunnel models do not compare well - especially near protuberances

- In general the maximum dynamic pressure or supersonic condition flight measurements greatly exceed wind tunnel measurements 